Supporting Information-2 (copies of spectrum)

A Simple Biomimetic Synthesis of dl-Chamaejasmine, a Unique 3,3'-Biflavanone

Wei-Dong Z. Li* and Bao-Chun Ma

State Key Laboratory of Applied Organic Chemistry, Lanzhou University, Lanzhou 730000, China

\title{
Table of Contents (spectrum)
}

1. 3-Iodonaringenin trimethyl ethers (cis- and trans-9)...................S2-S6

2. 3-Bromonaringenin trimethyl ethers (cis and trans)...................S7-S10

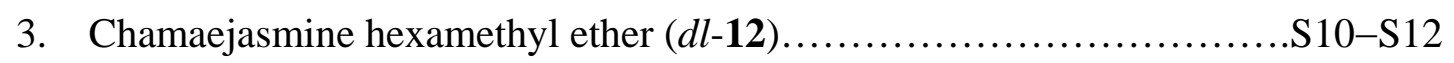

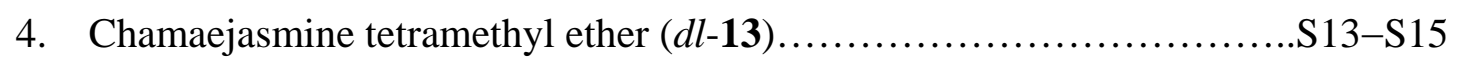

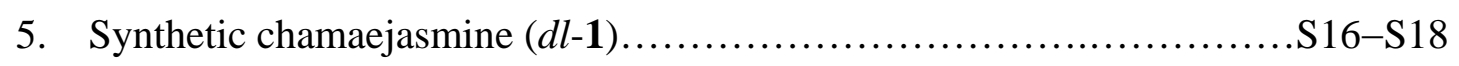

6. Authentic chamaejasmine racemate.................................S18-S20

7. 3-Halogenated flavanones (cis- and trans-5)........................S21-S24

8. 4'-Methoxy-3-Iodoflavanones (cis- and trans-7).....................S25-S27

9. 4', 5-Dimethoxy-3-Iodoflavanones (cis- and trans-8)...................S27-S29

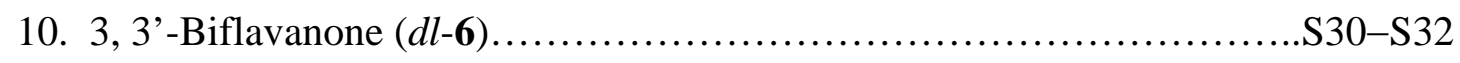

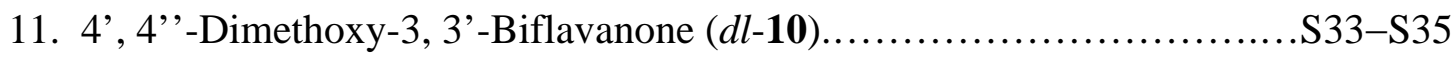

12. 4', 4', 5, 5'-Tetramethoxy-3, 3'-Biflavanone (dl-11)......................S35-S37 


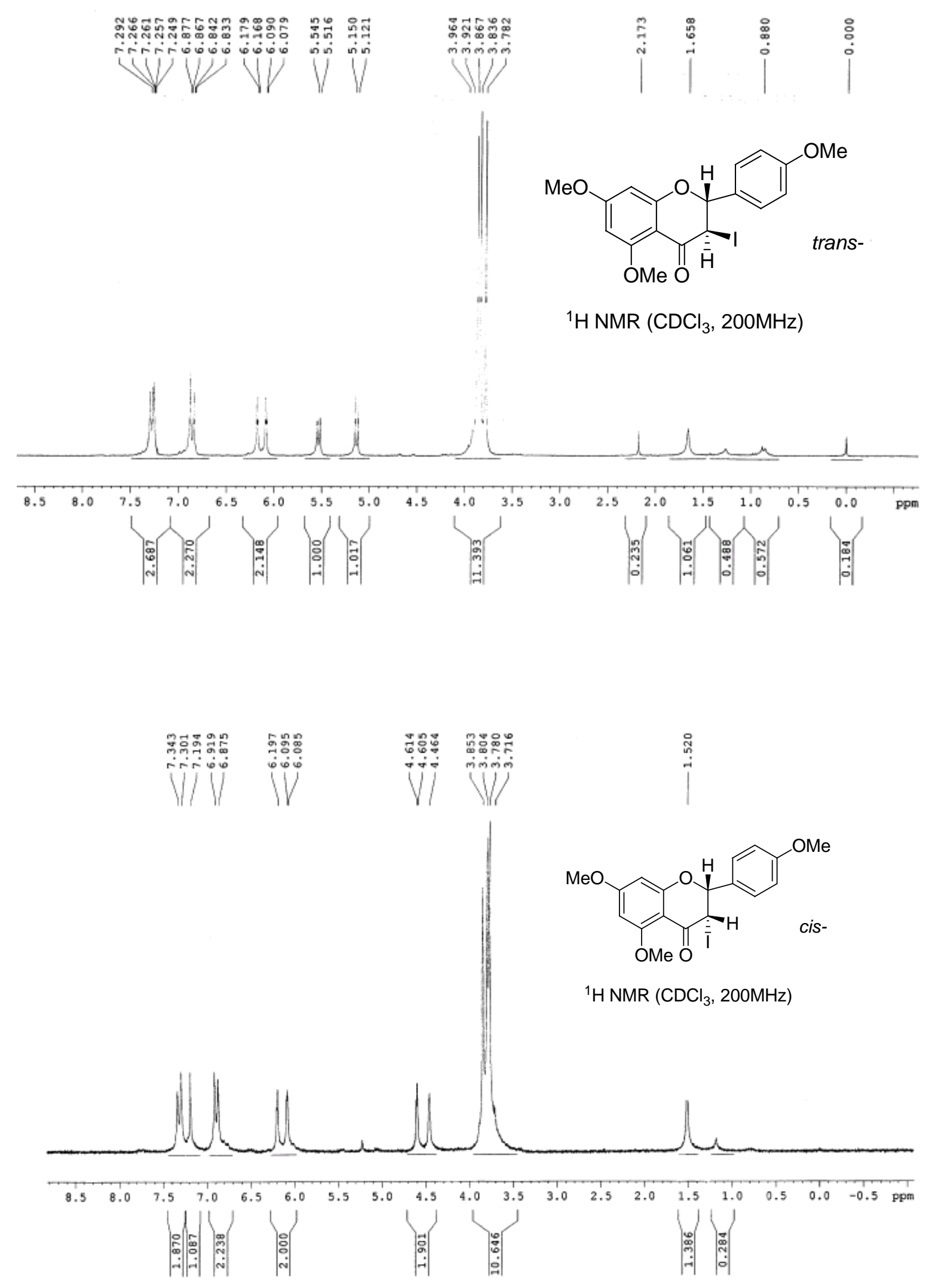




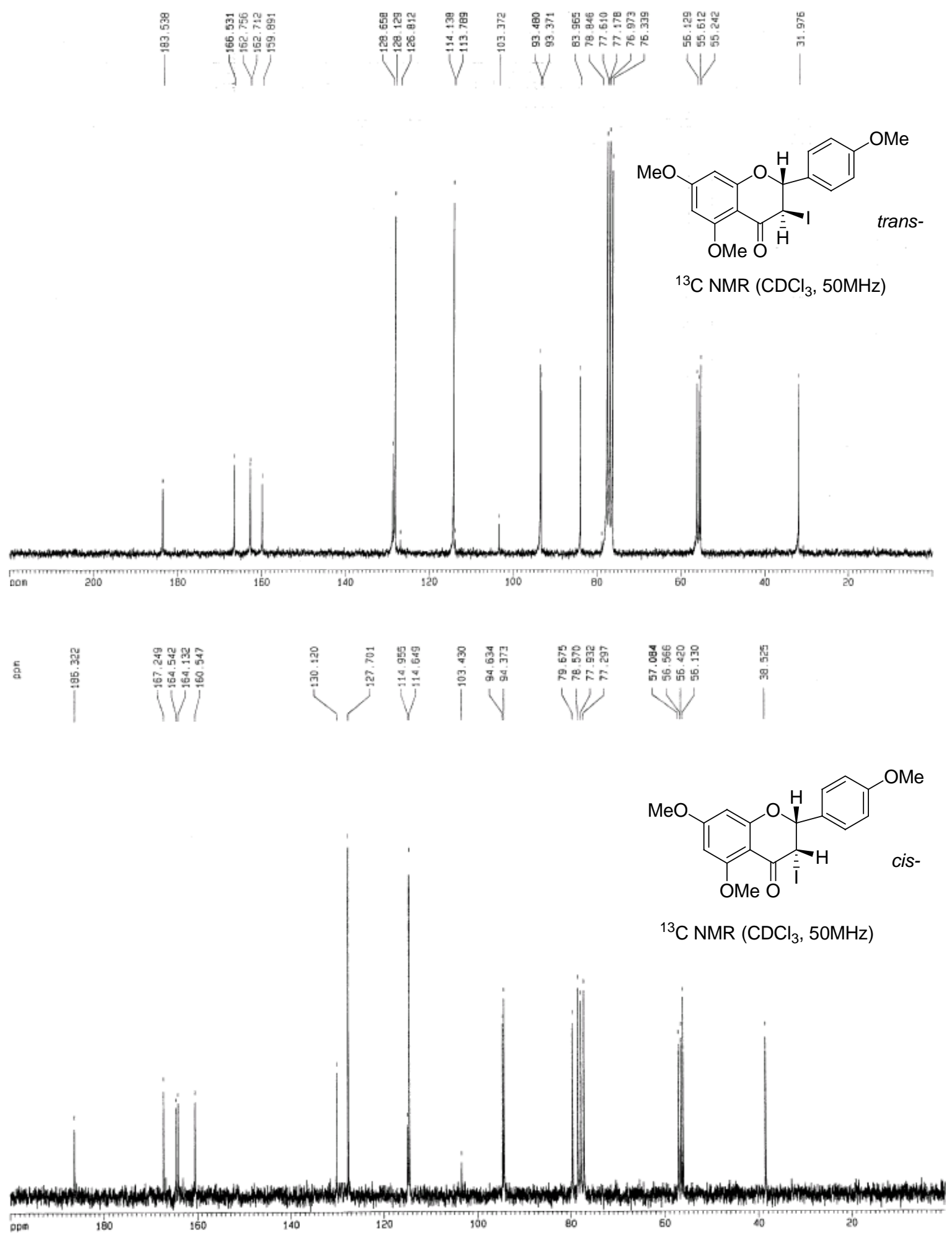



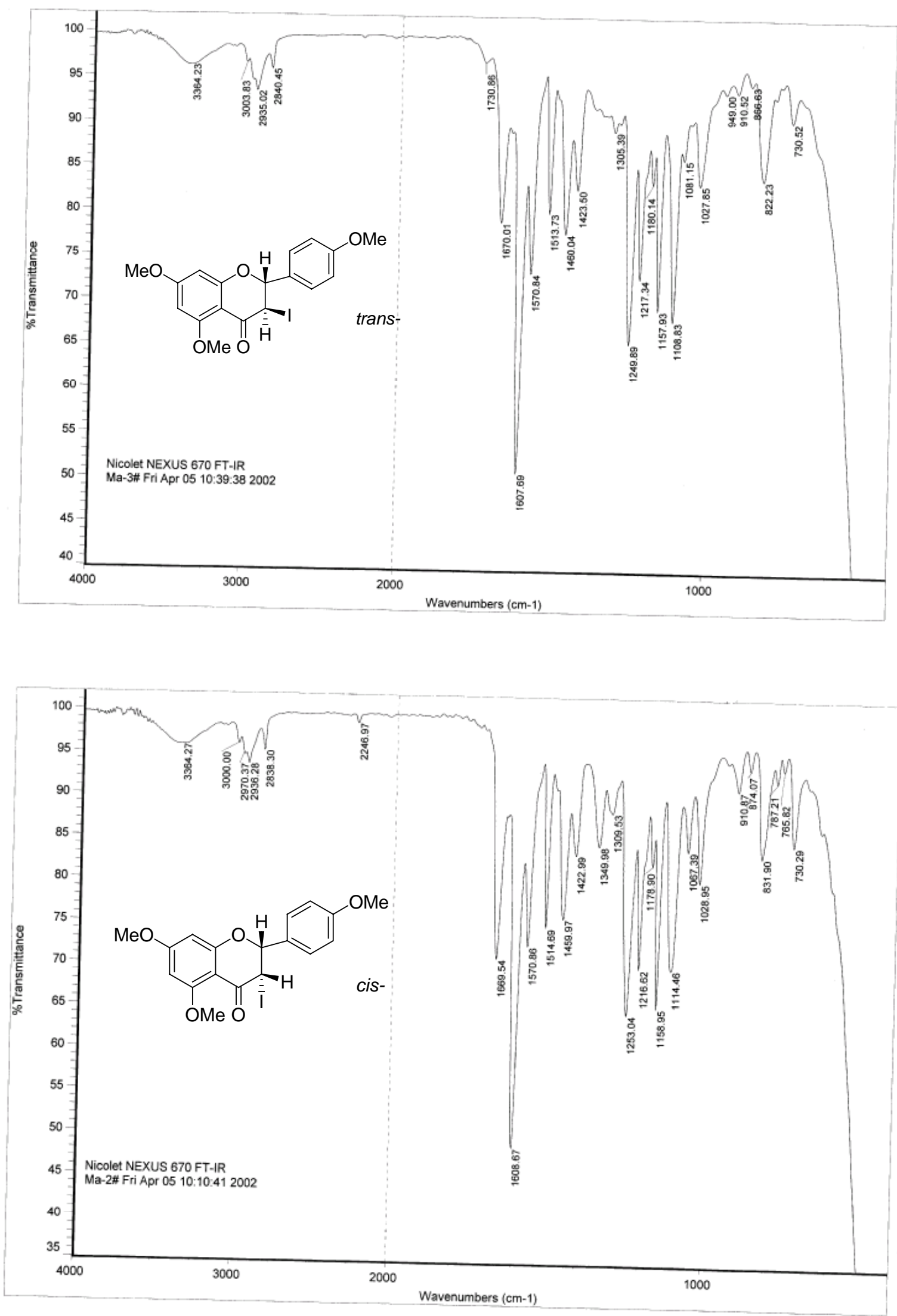
File : C: \HPCHEM $\backslash 1 \backslash D A T A \backslash 40438 . D$

Operator : 4 Apr $2002 \quad 11: 25$ using AcgMethod DIP700

Instrument : HP 5988

Sample Name: MA BAD-CHON, 3A\$, 440

Nise Info :

EIMS
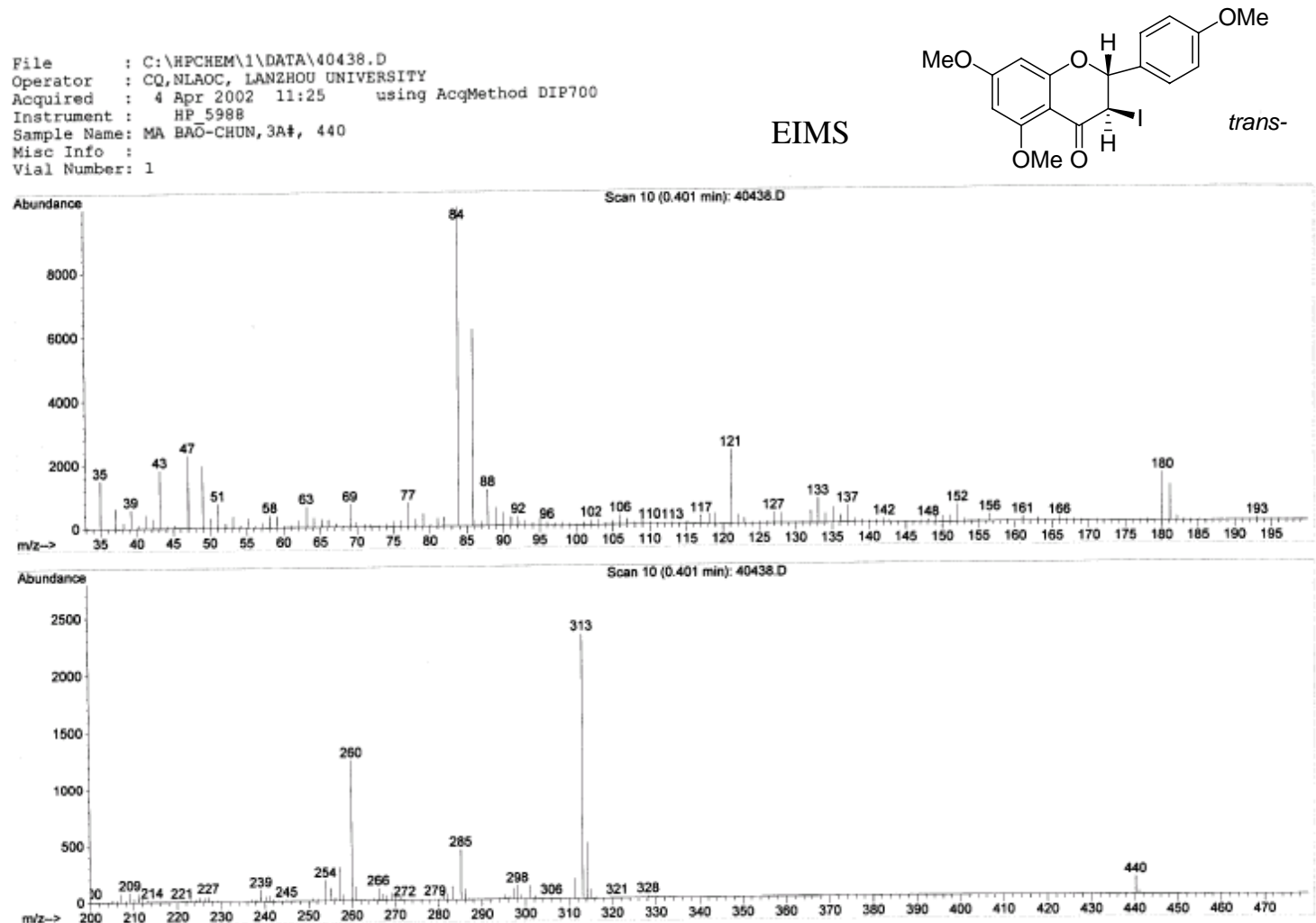

File

C: \HPCHEM $1 \backslash$ DATA 40437 .D

Operator : CQ, NLROC, LANZHCO UNTVERSITY AeqMethod DIP?

Instrument : HP 598

Sample Name: MA BAŌ-CHUN, 2A4, 440

lal Number:

EIMS
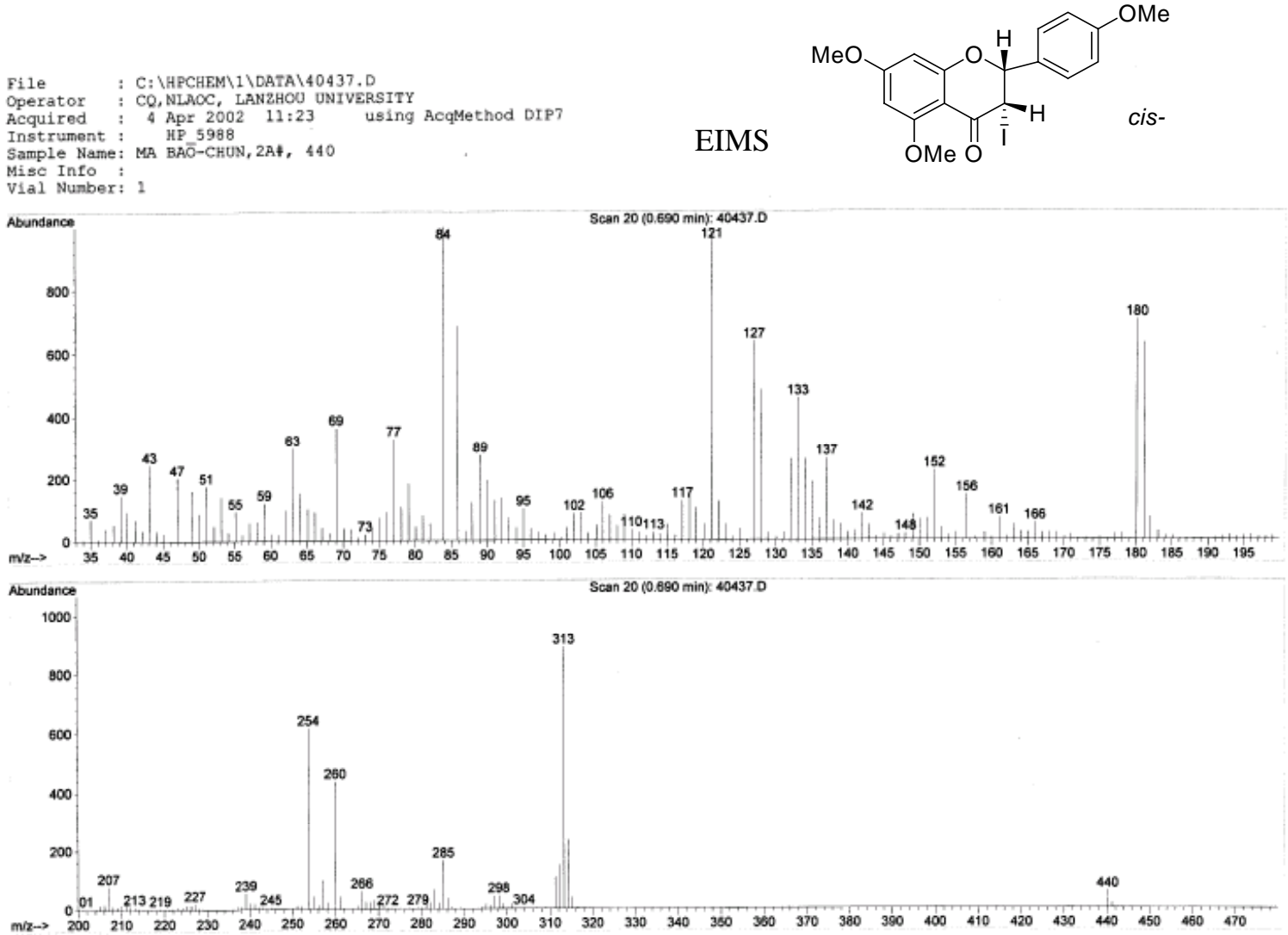


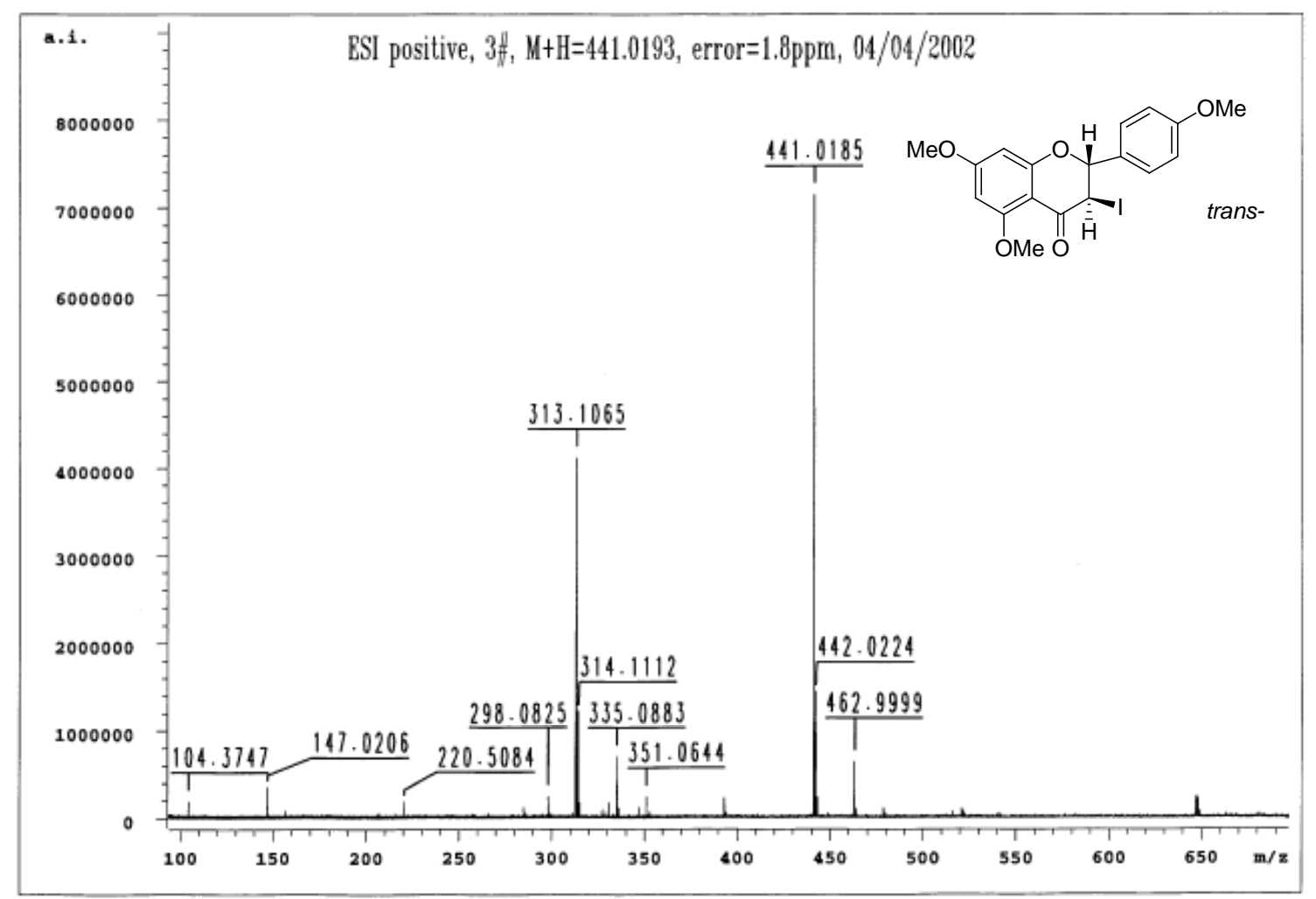

/u/data/TRAINING/mabaochun0404/3/patata/1 xspec Thu Apr 4 17:13:41 2002

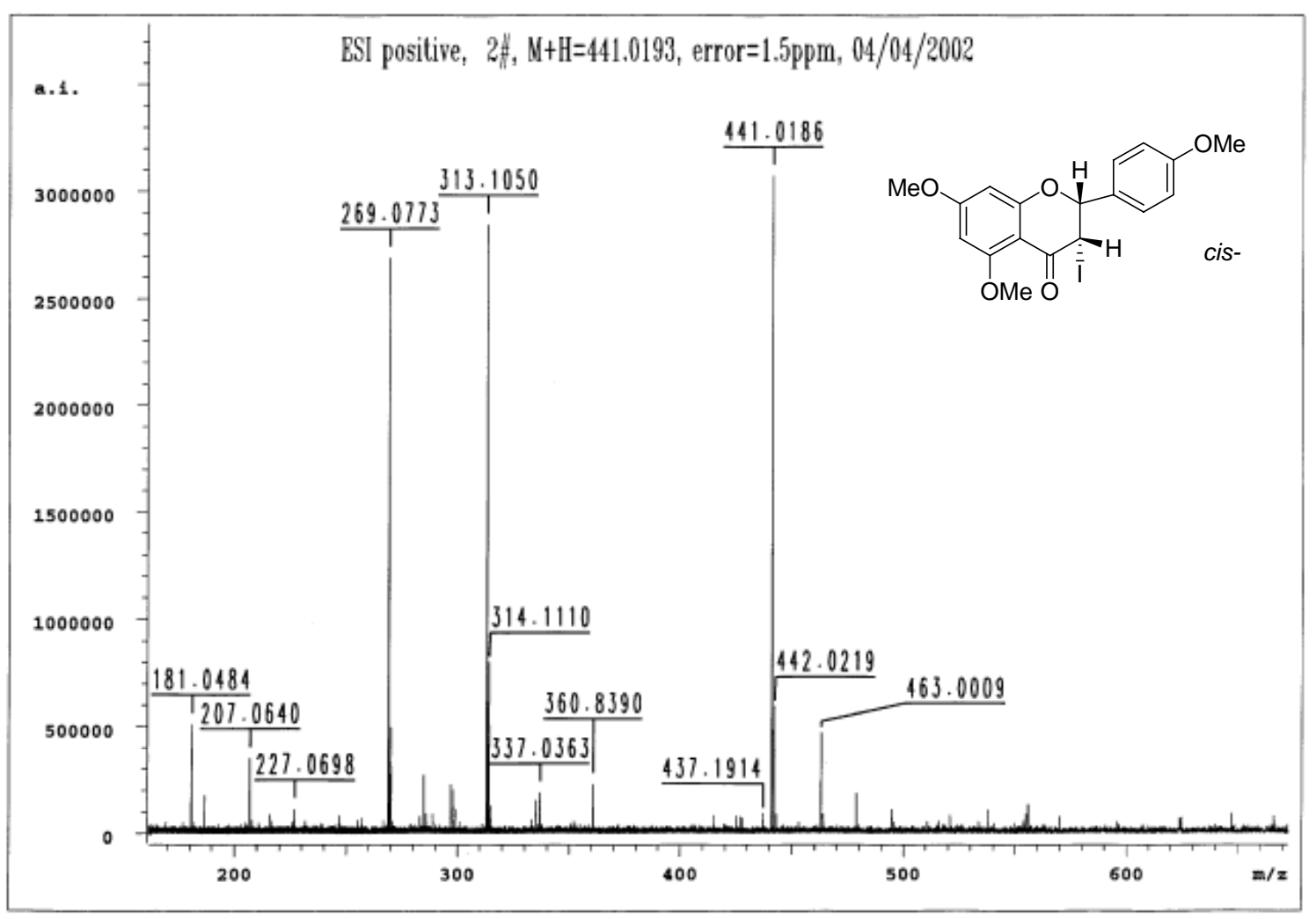

/u/data/TRAINING/mabaochun0404/2/pdata/1 xspec Thu Apr 4 17:15:12 2002 

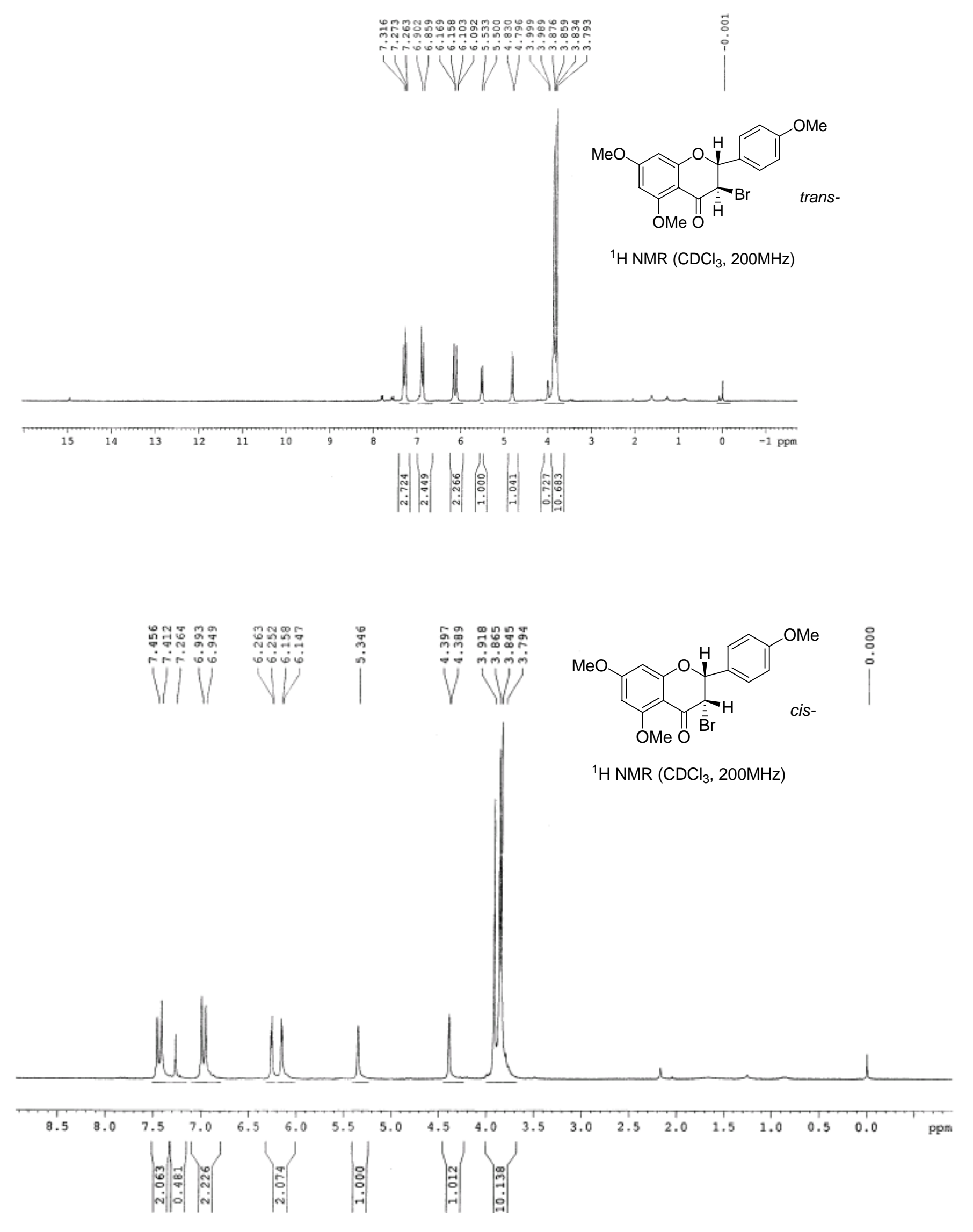


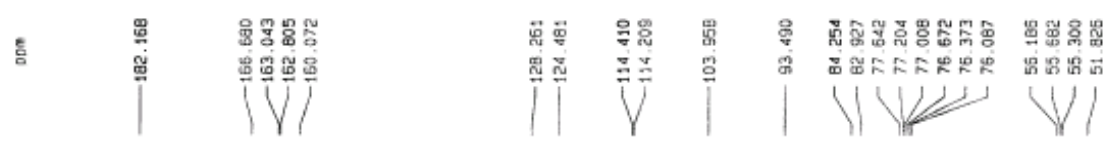

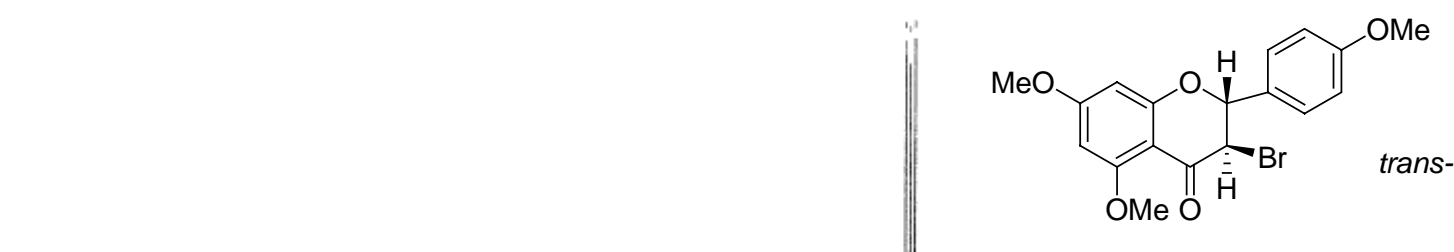

${ }^{13} \mathrm{C}$ NMR $\left(\mathrm{CDCl}_{3}, 50 \mathrm{MHz}\right)$

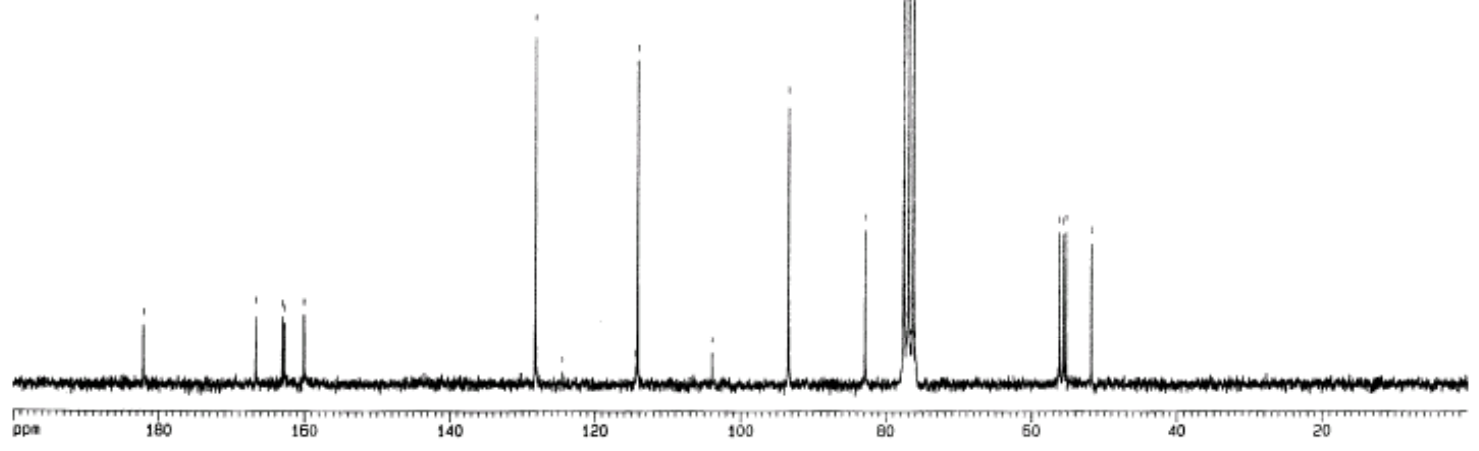

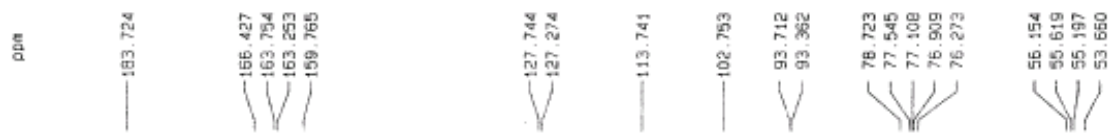

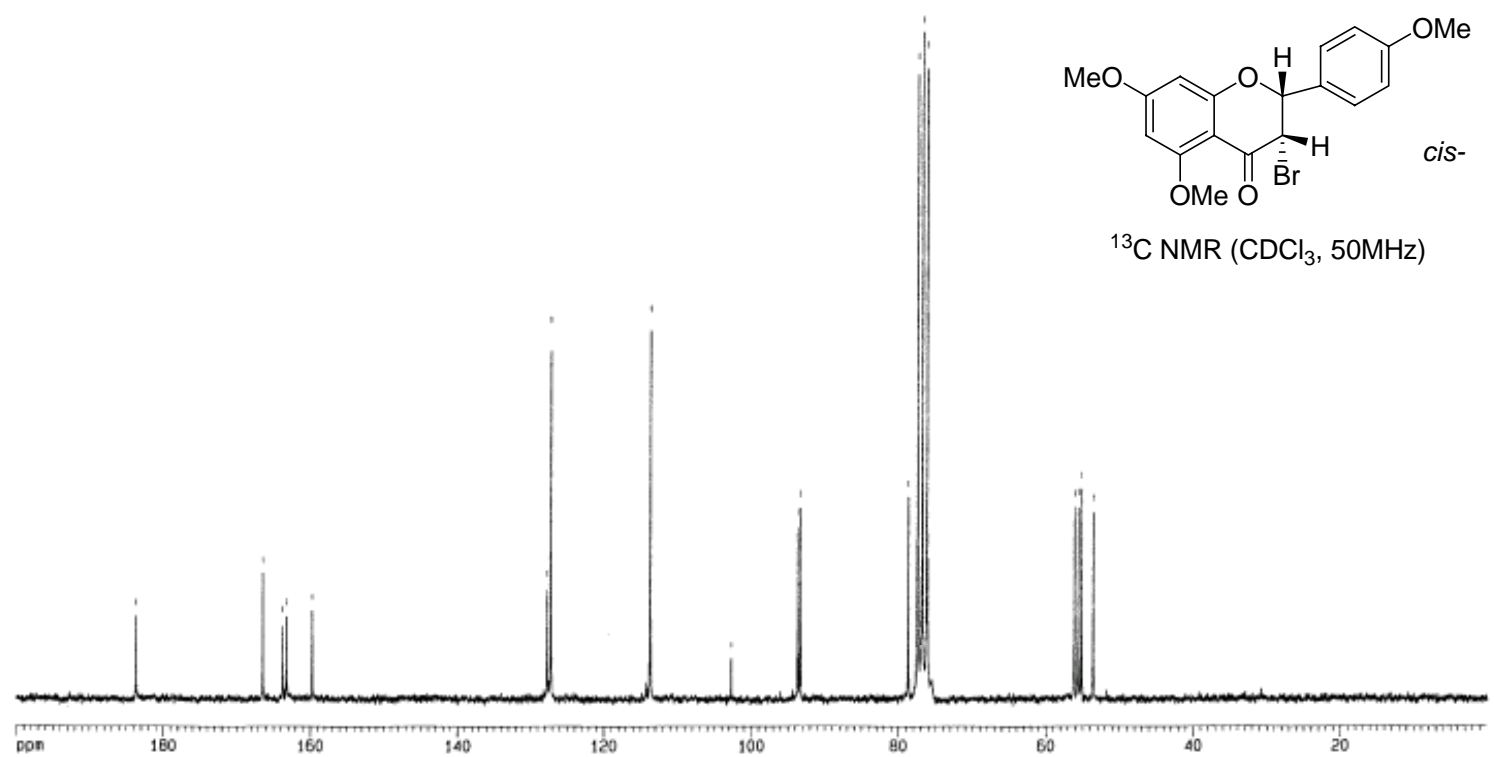



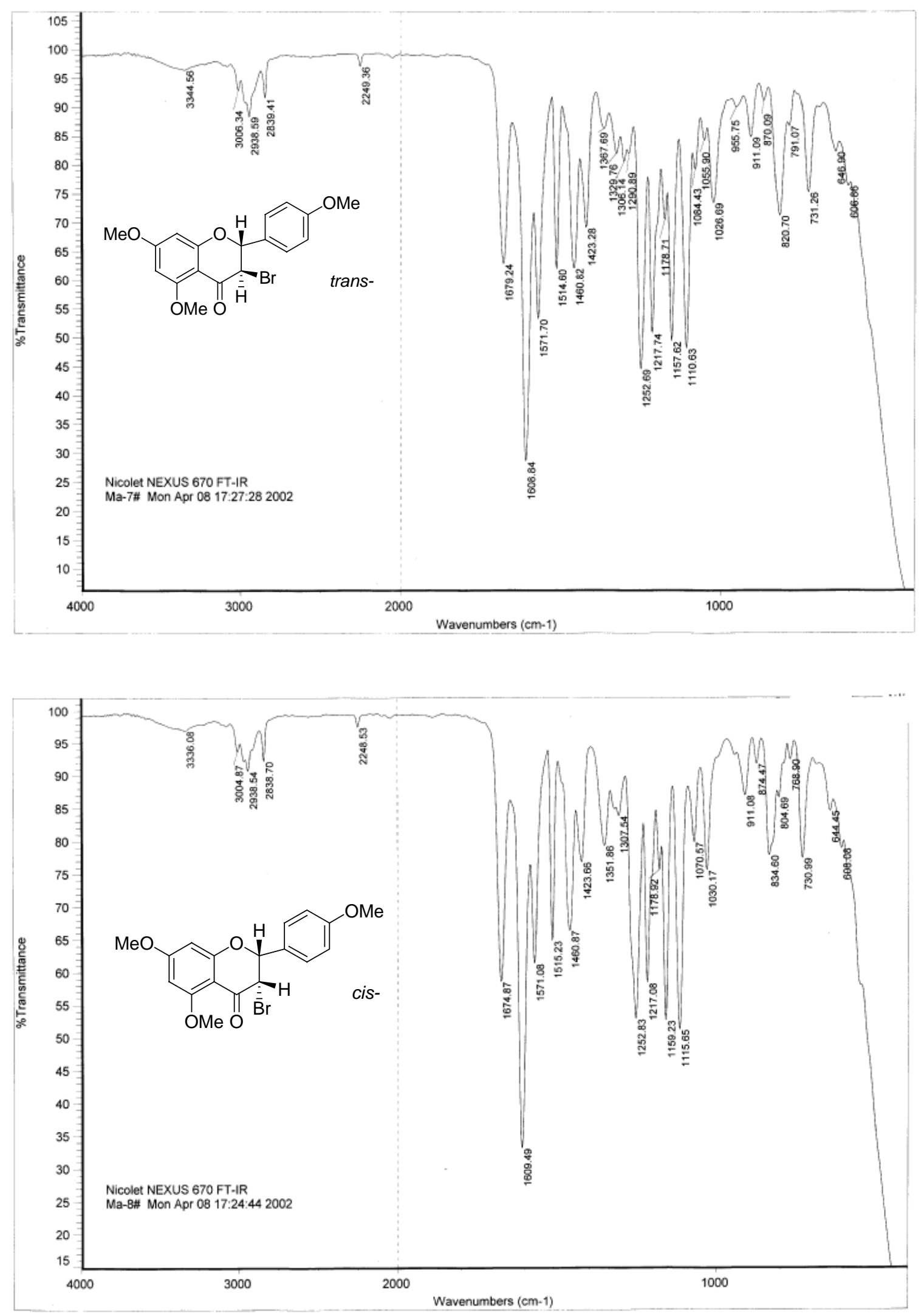
Acquired : 9 Apr 2002 11:15 using Acckethod DIP700

Sarple Name: MA BAD̄-CHUN, 392, BH

Misc Info : 1
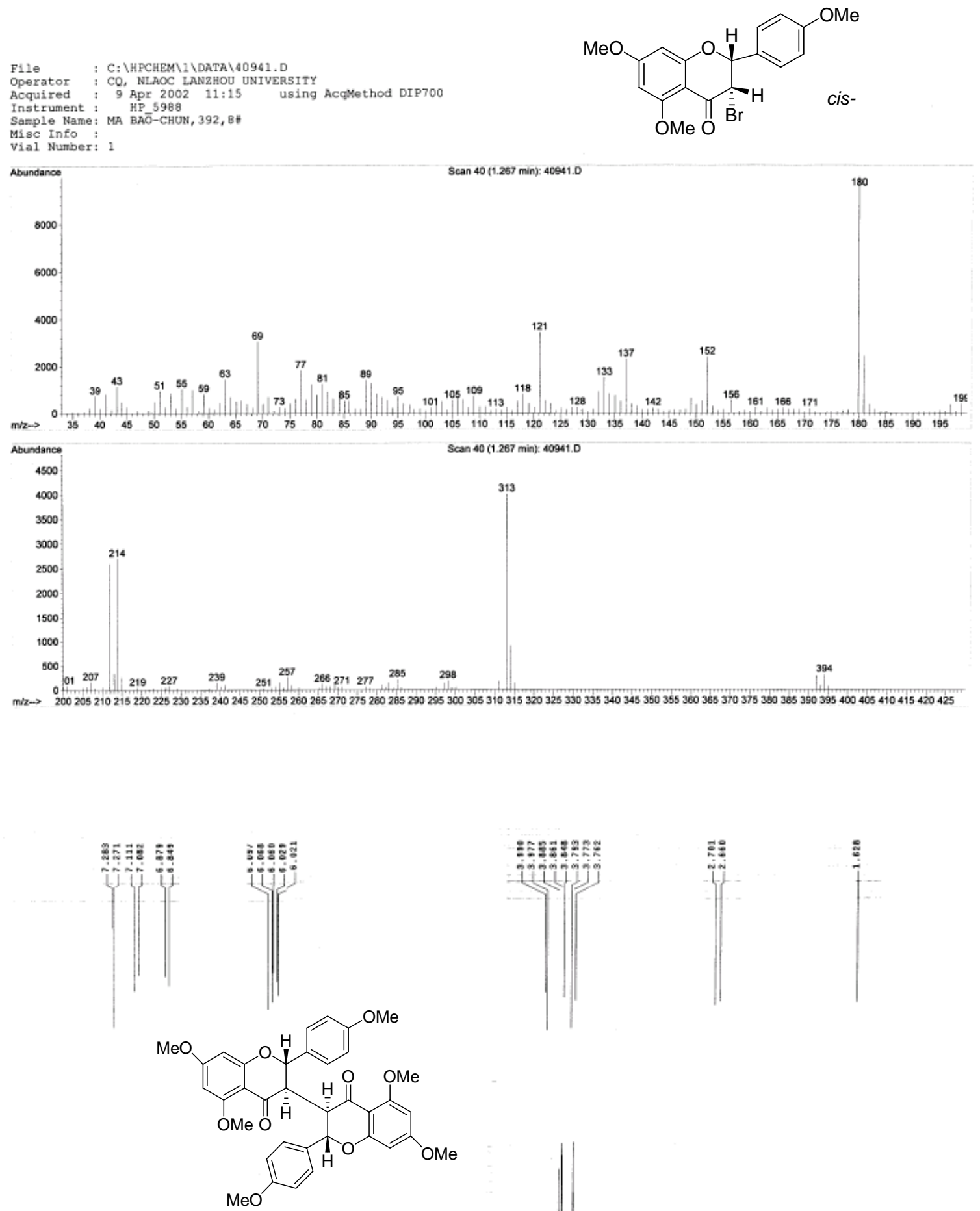

${ }^{1} \mathrm{H} \mathrm{NMR}\left(\mathrm{CDCl}_{3}, 300 \mathrm{MHz}\right)$

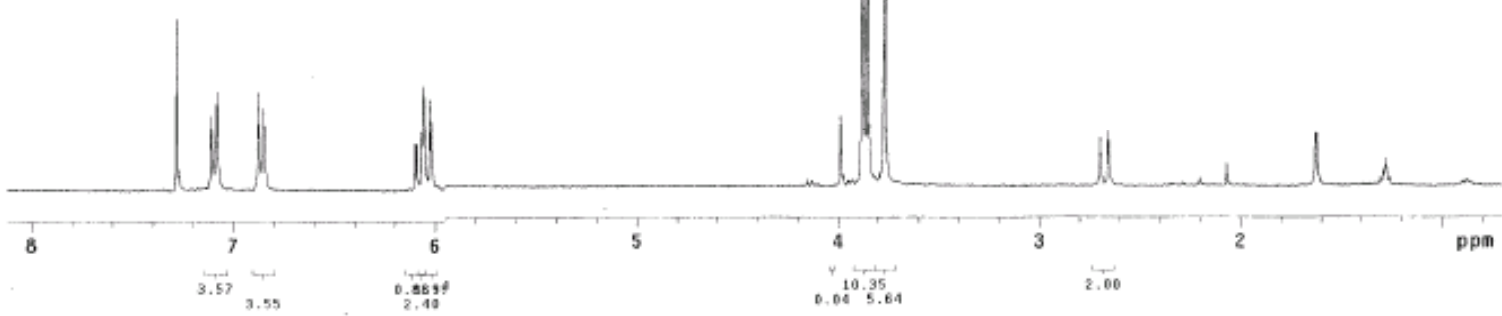



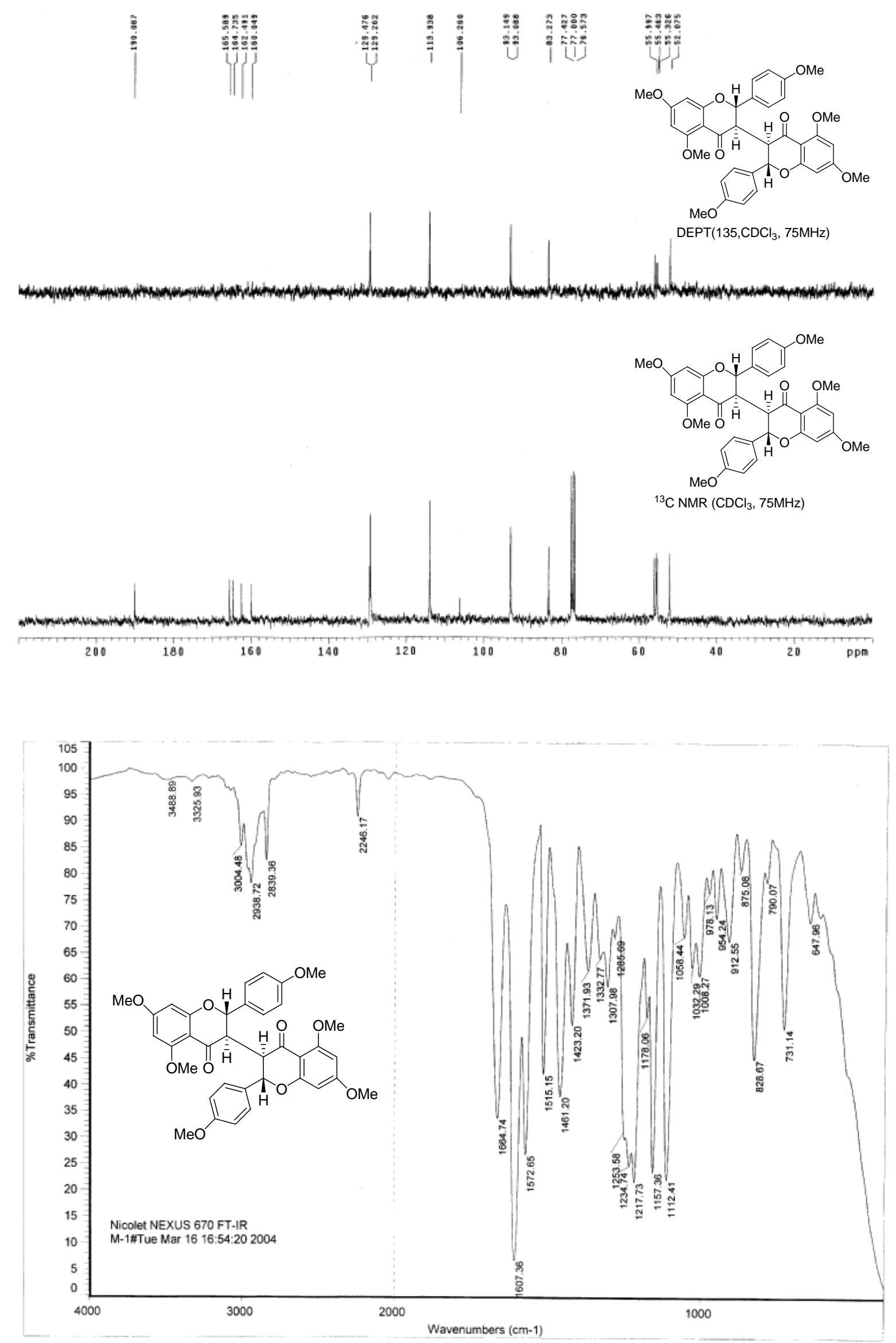

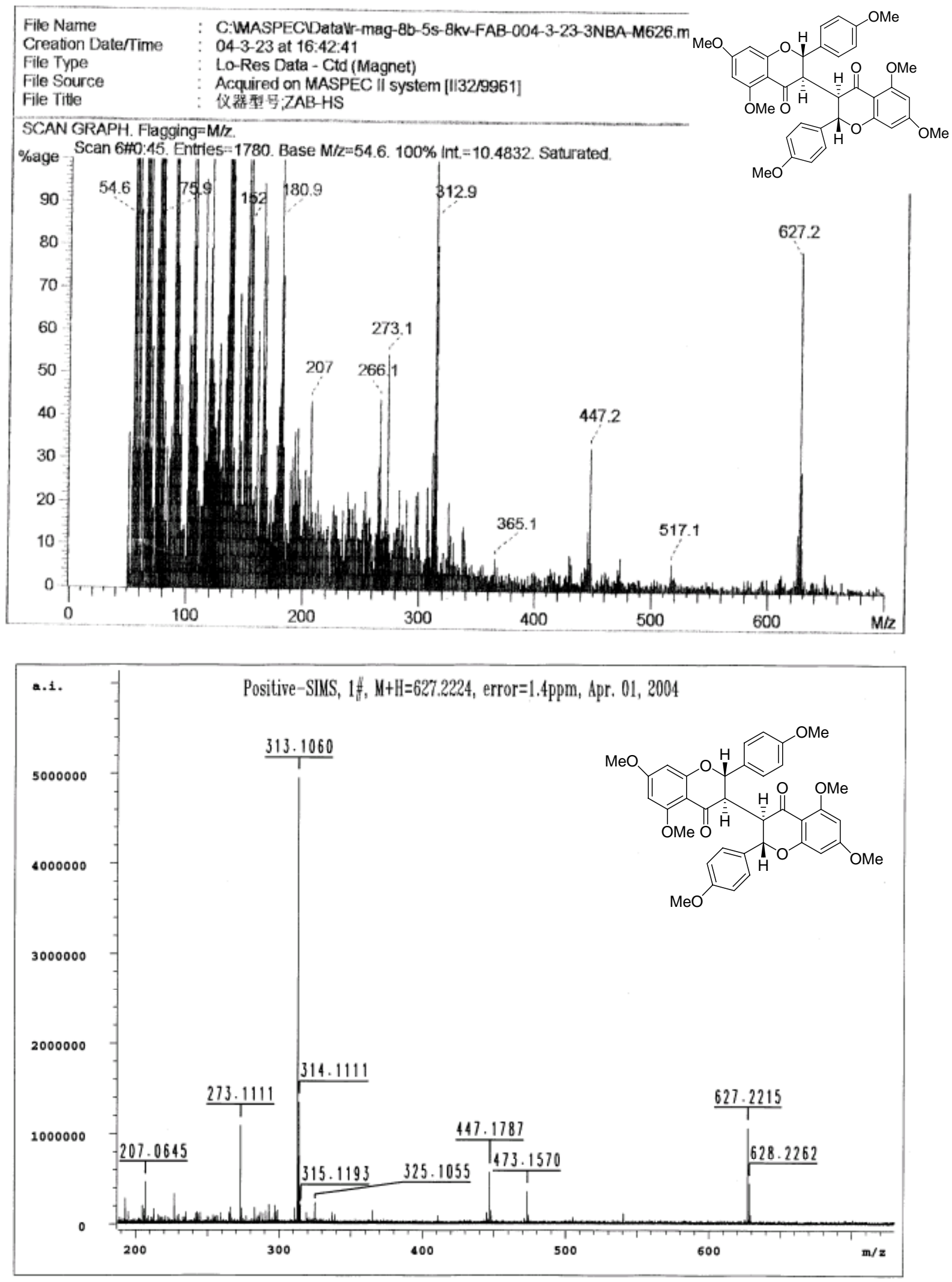

/u/data/TRAINING/mabaochun0401/2/pata/1 xspec Thu Apr 1 11:19:58 2004 

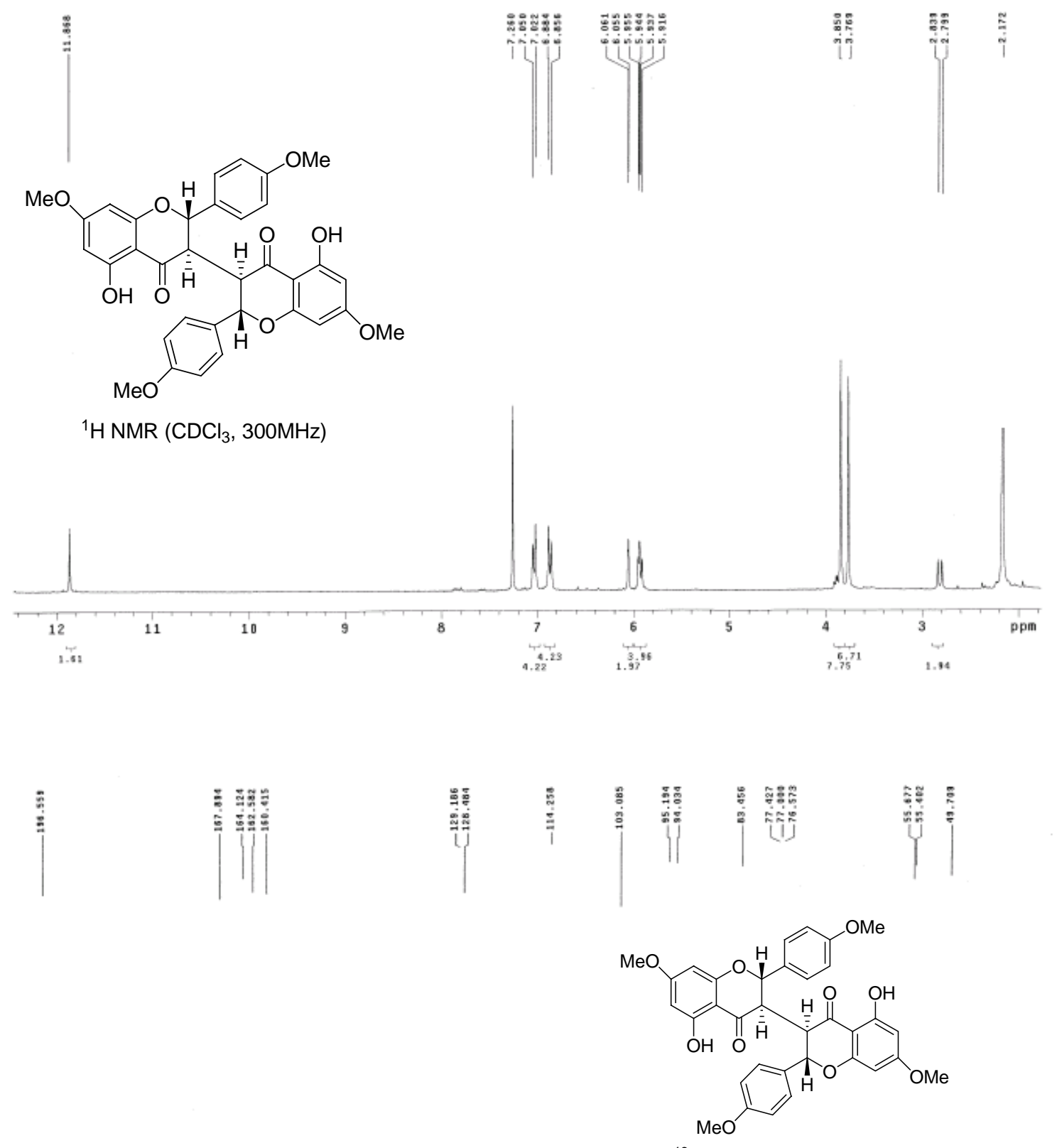

$\left.{ }^{13} \mathrm{C} \mathrm{NMR} \mathrm{(CDCl} 3,75 \mathrm{MHz}\right)$

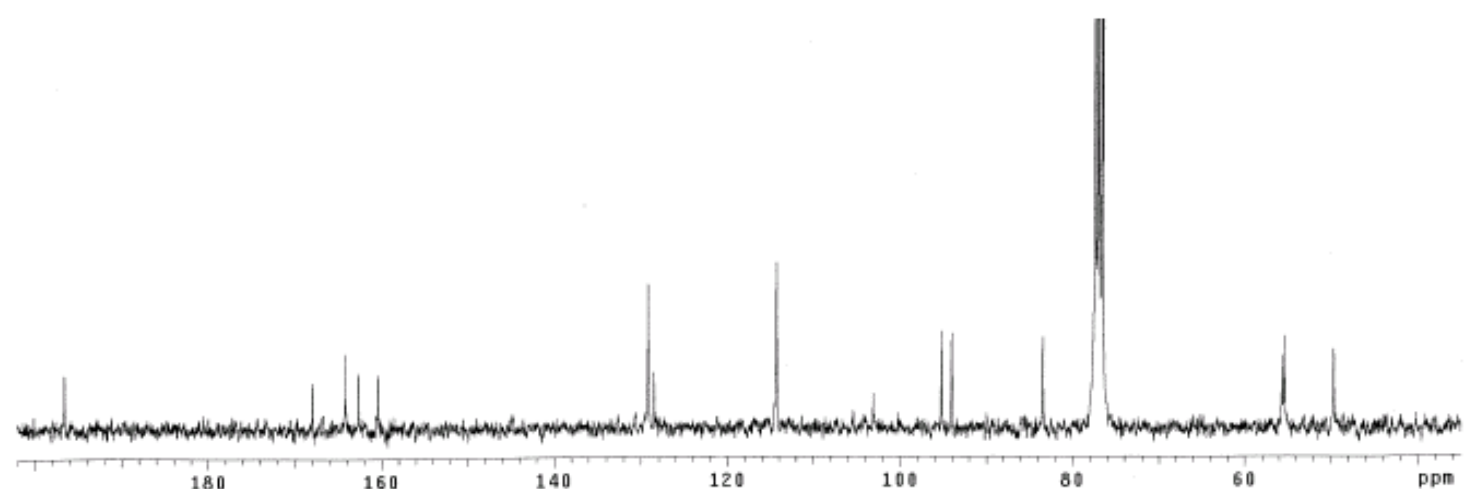



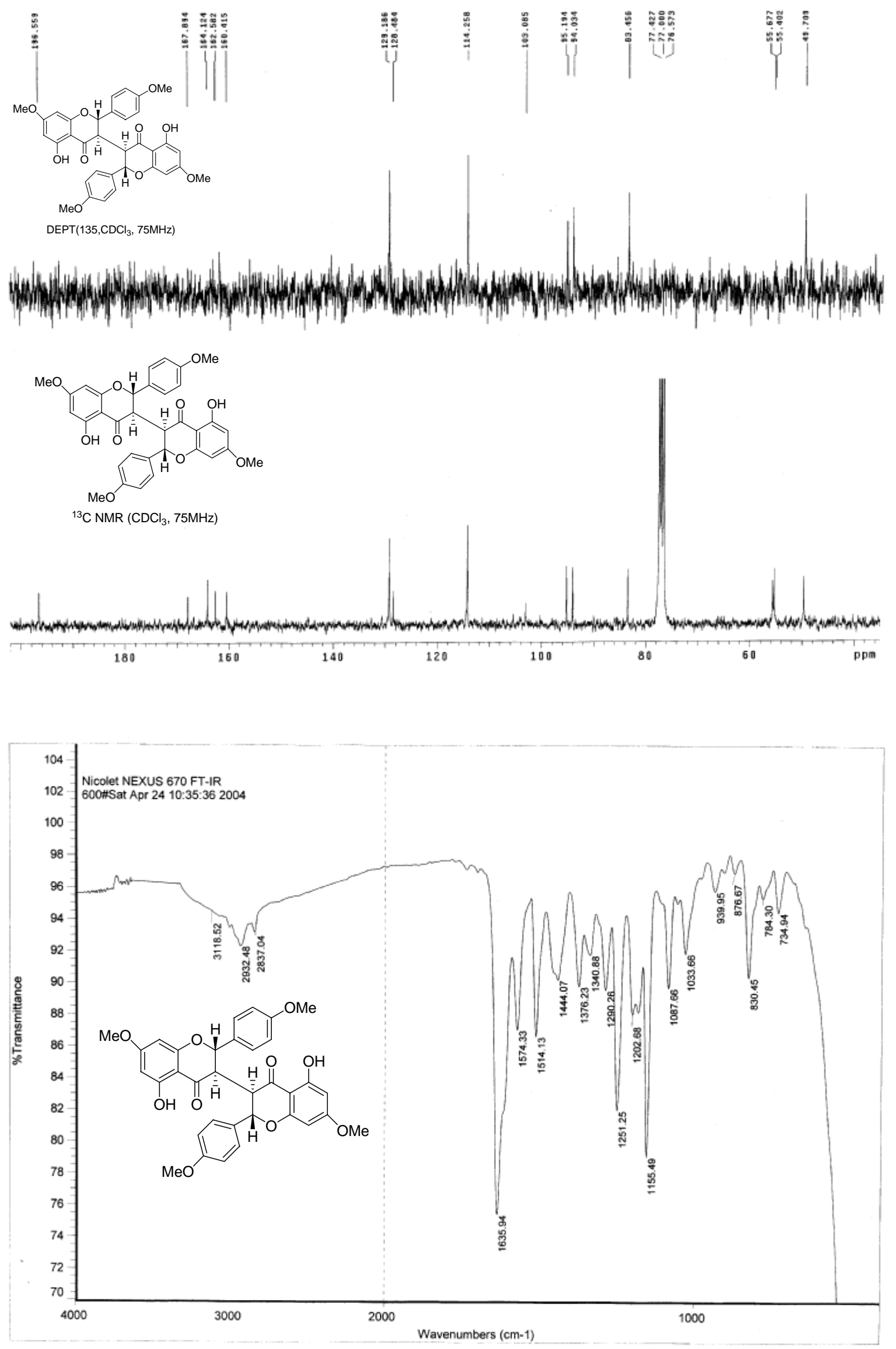

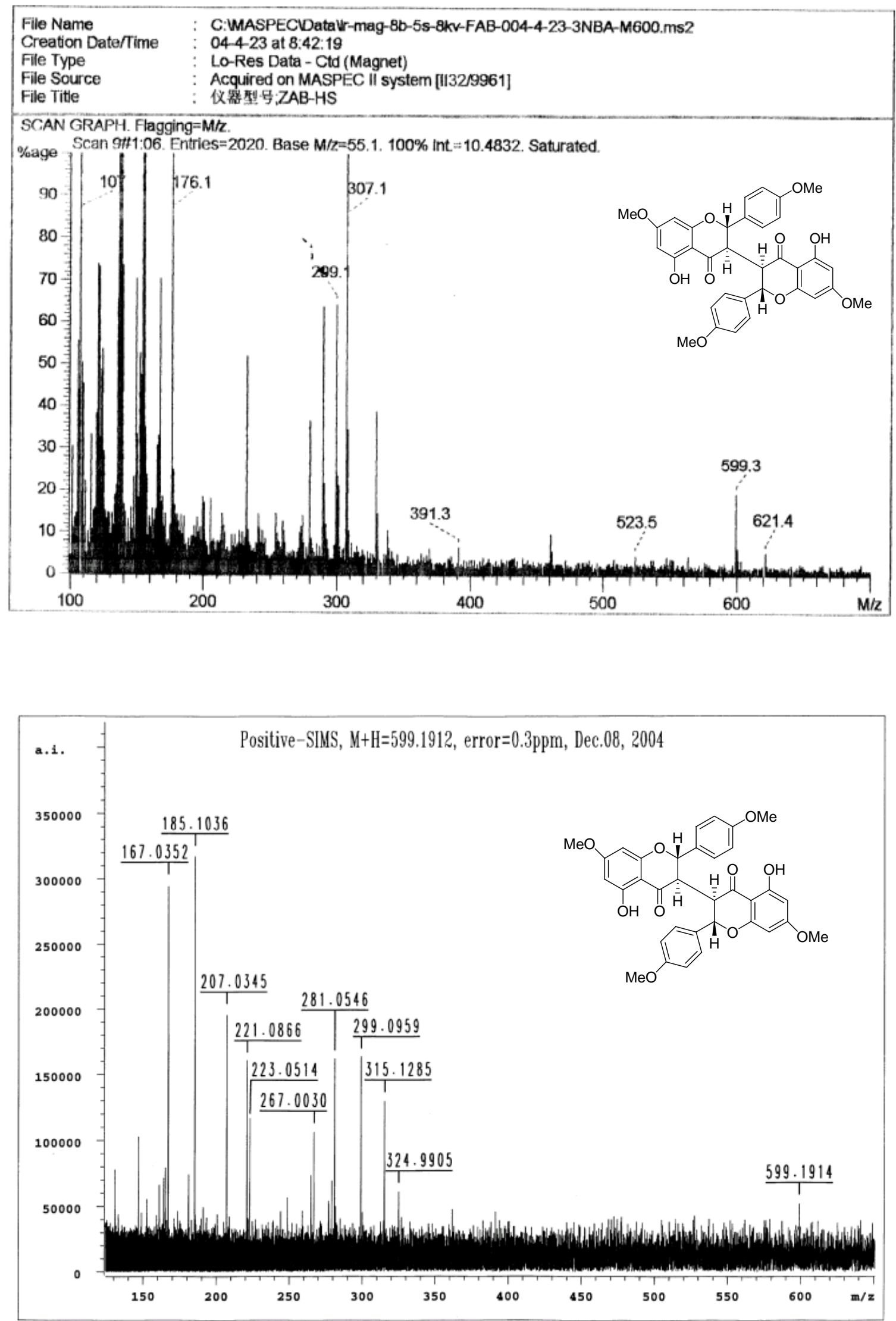

/u/data/TRAINING/mabaochun1209/1/pdata/1 xspec Thu Dec 9 16:34:10 2004 

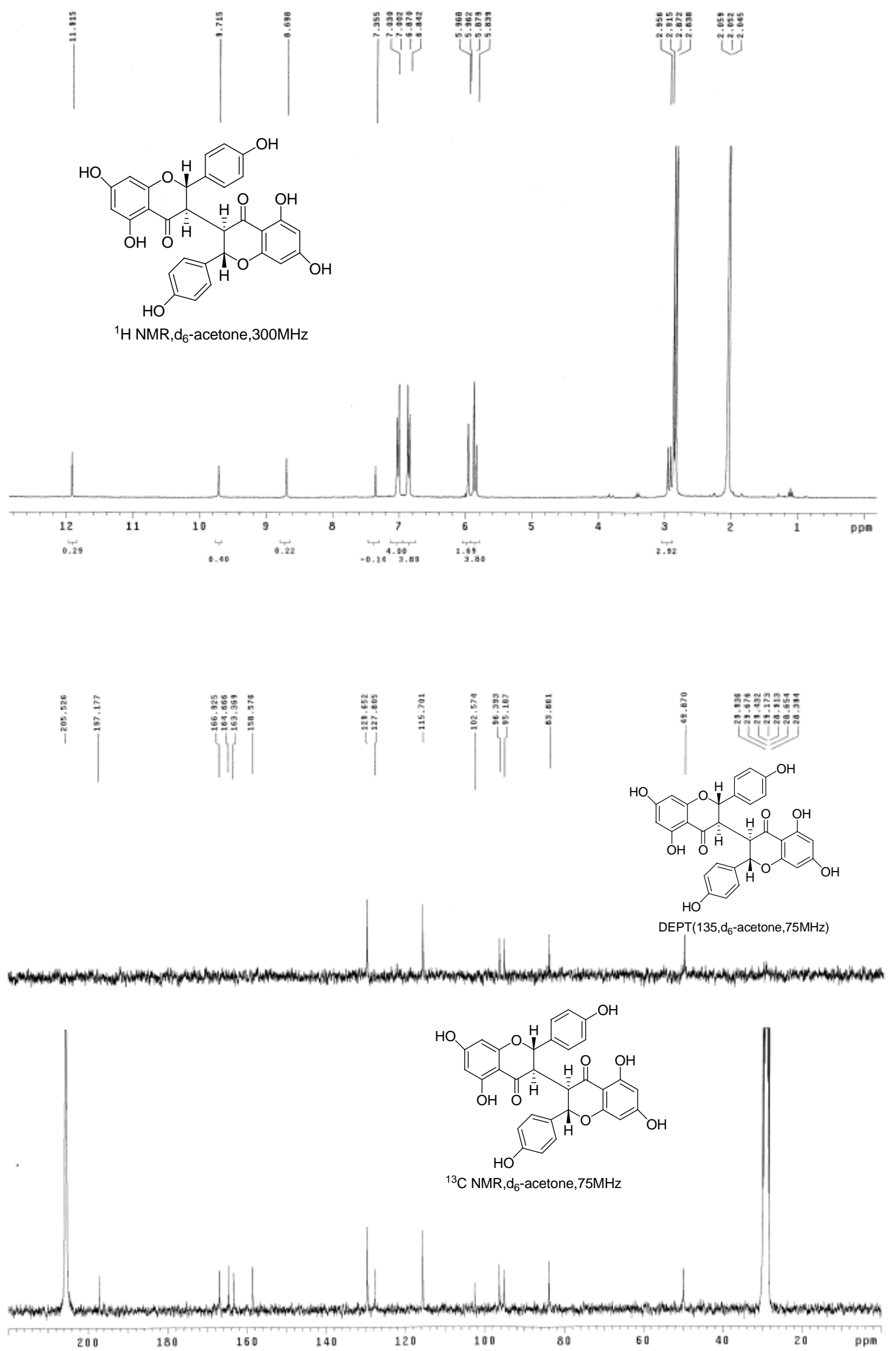

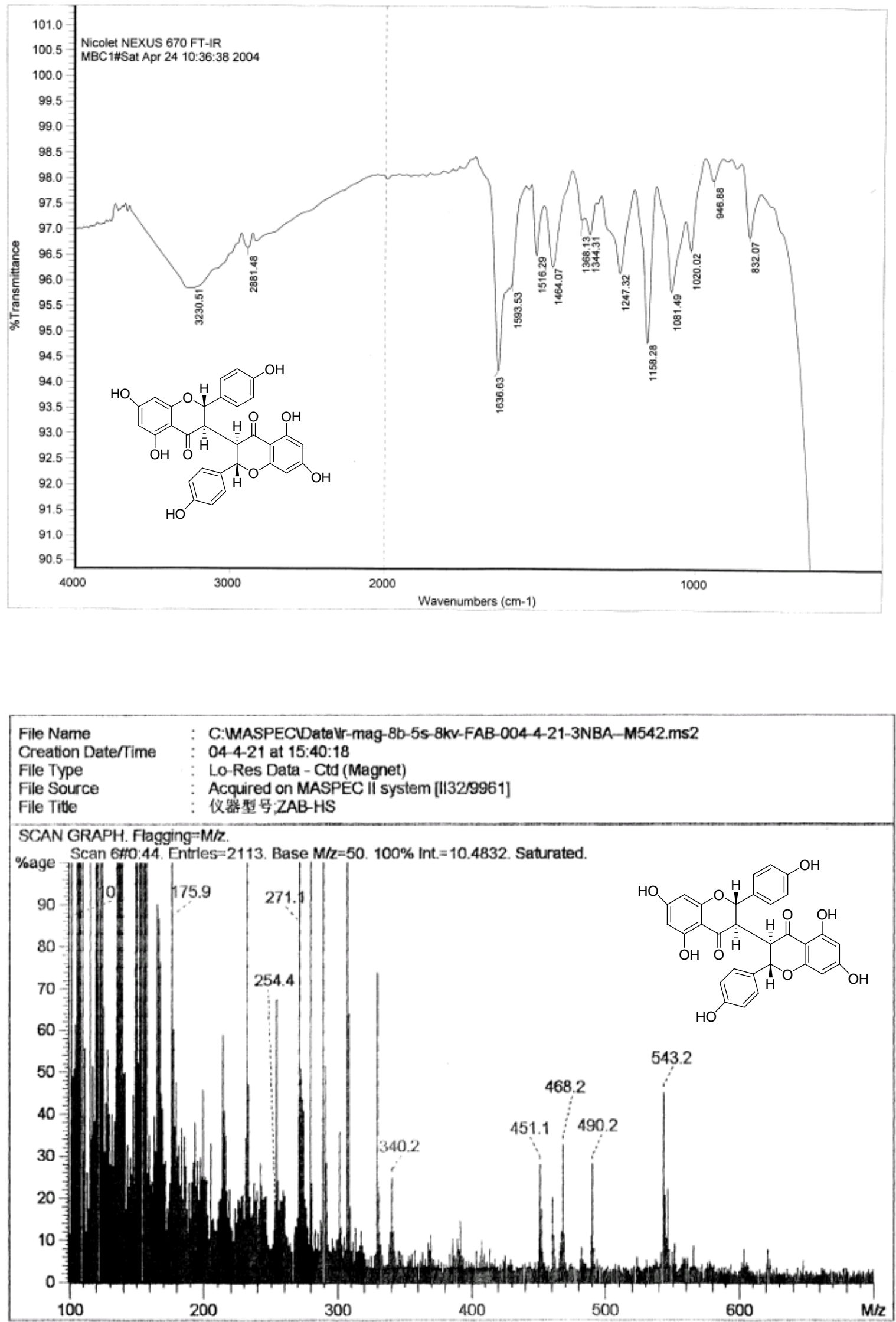


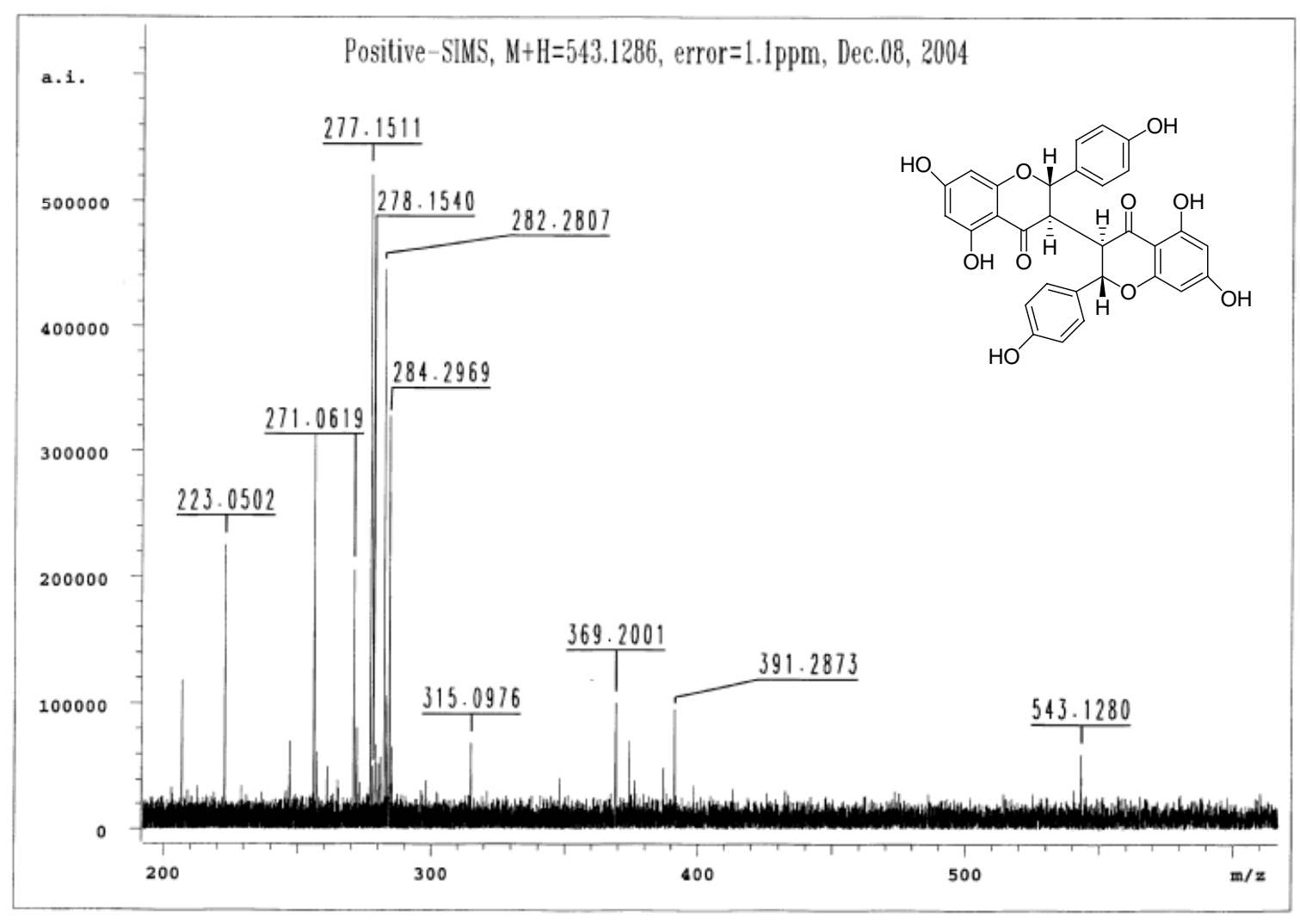

/u/data/TRAINING/mabaochun1208/1/Ddata/1 xspec Wed Dec 8 16:46:01 2004

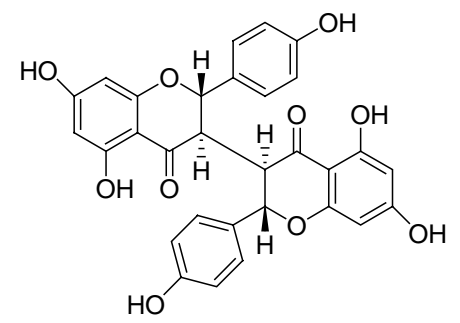

${ }^{1} \mathrm{H} \mathrm{NMR}_{\mathrm{d}} \mathrm{d}_{6}$-acetone, $200 \mathrm{MHz}$

Chamaejasmine authetic sample

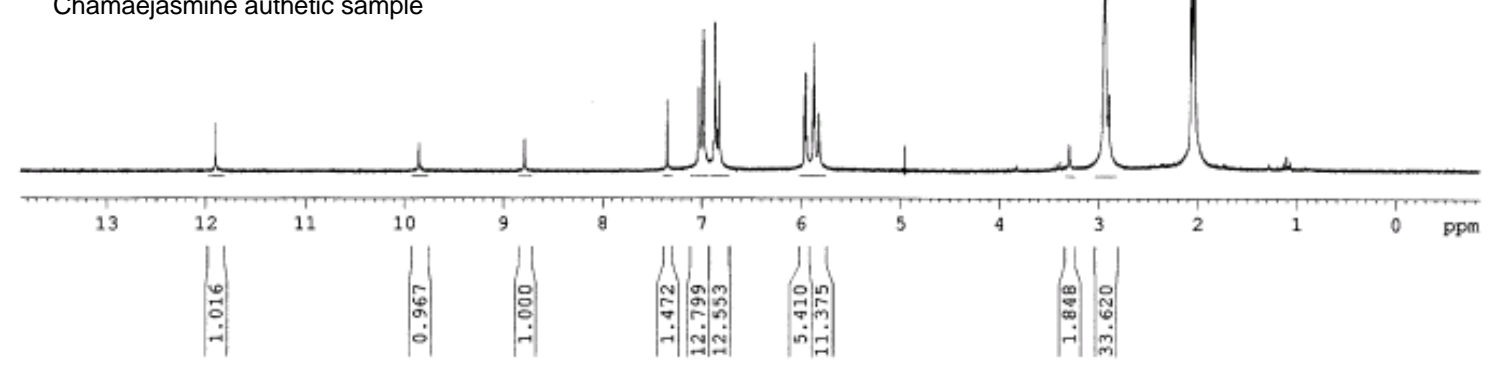



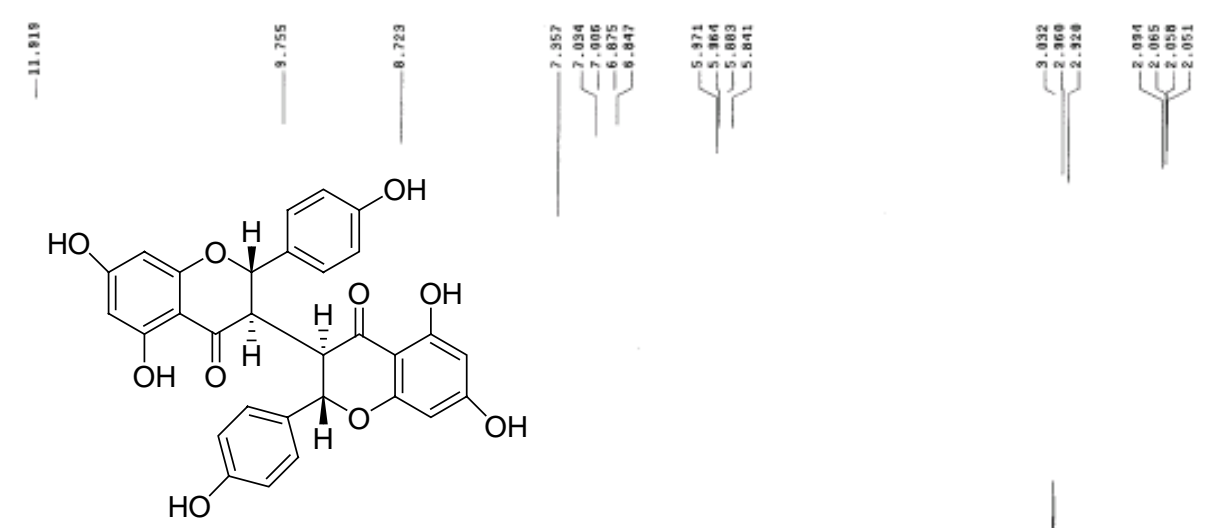

${ }^{1} \mathrm{H}$ NMR, $\mathrm{d}_{6}$-acetone, $300 \mathrm{MHz}$

Chamaejasmine authetic sample
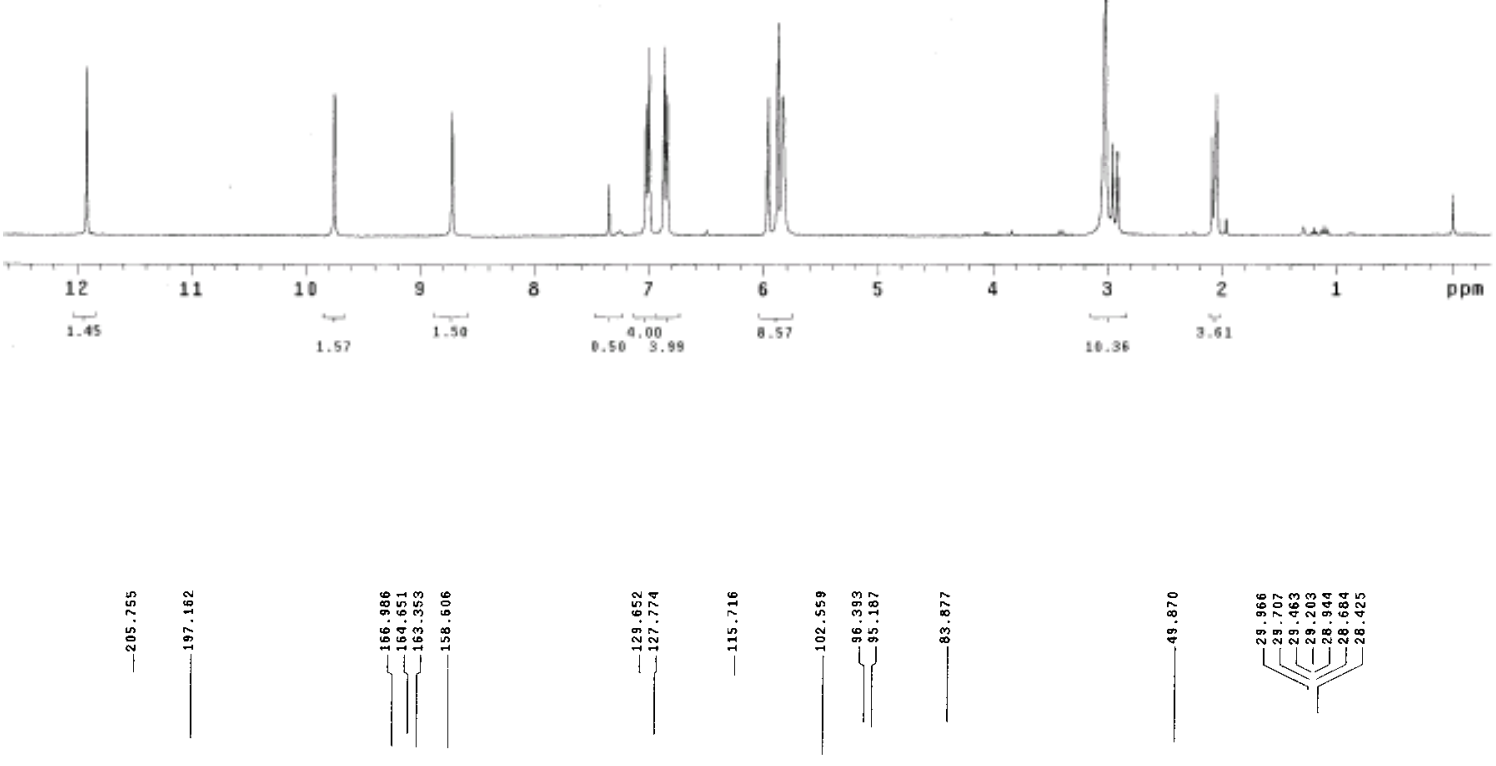

$\operatorname{DEPT}\left(135, \mathrm{~d}_{6}\right.$-acetone, $\left.75 \mathrm{MHz}\right)$

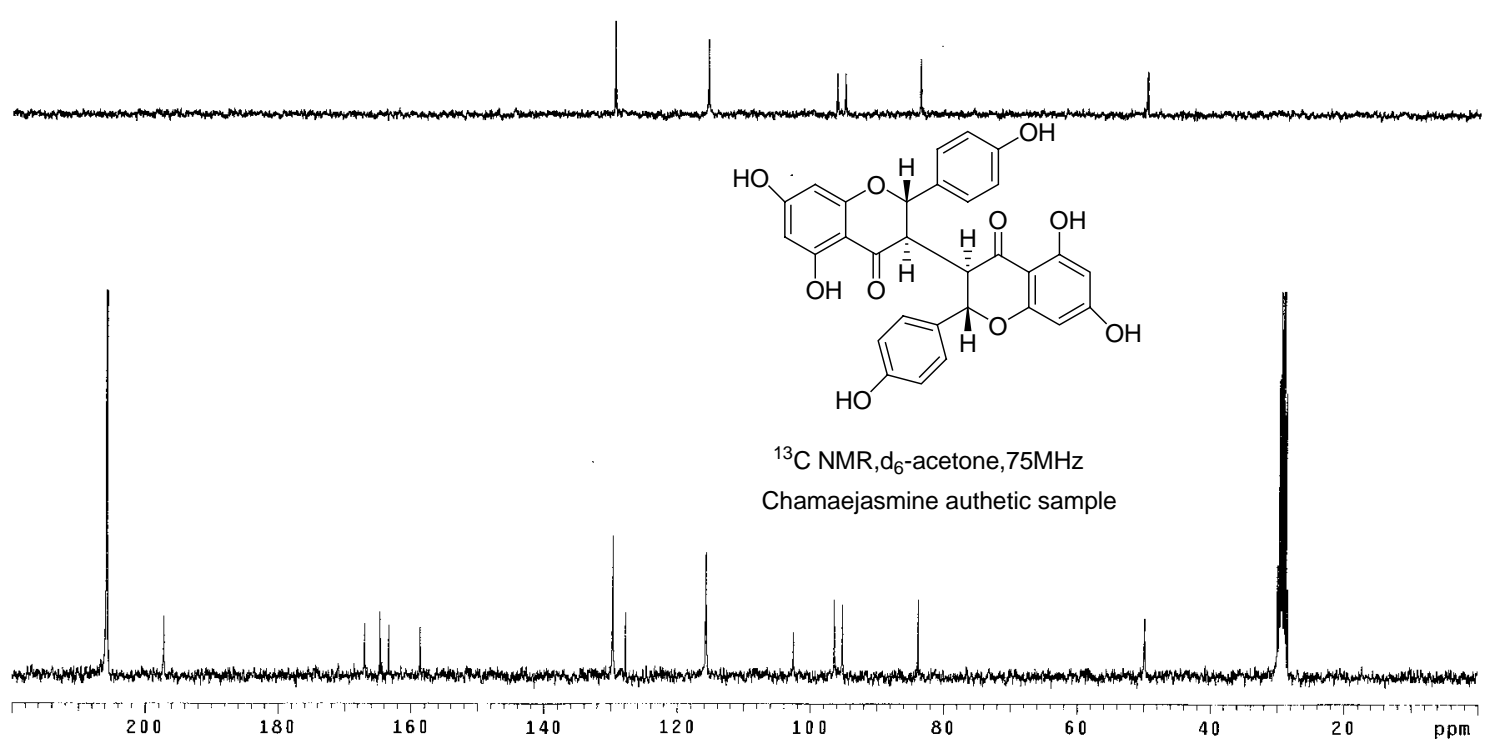



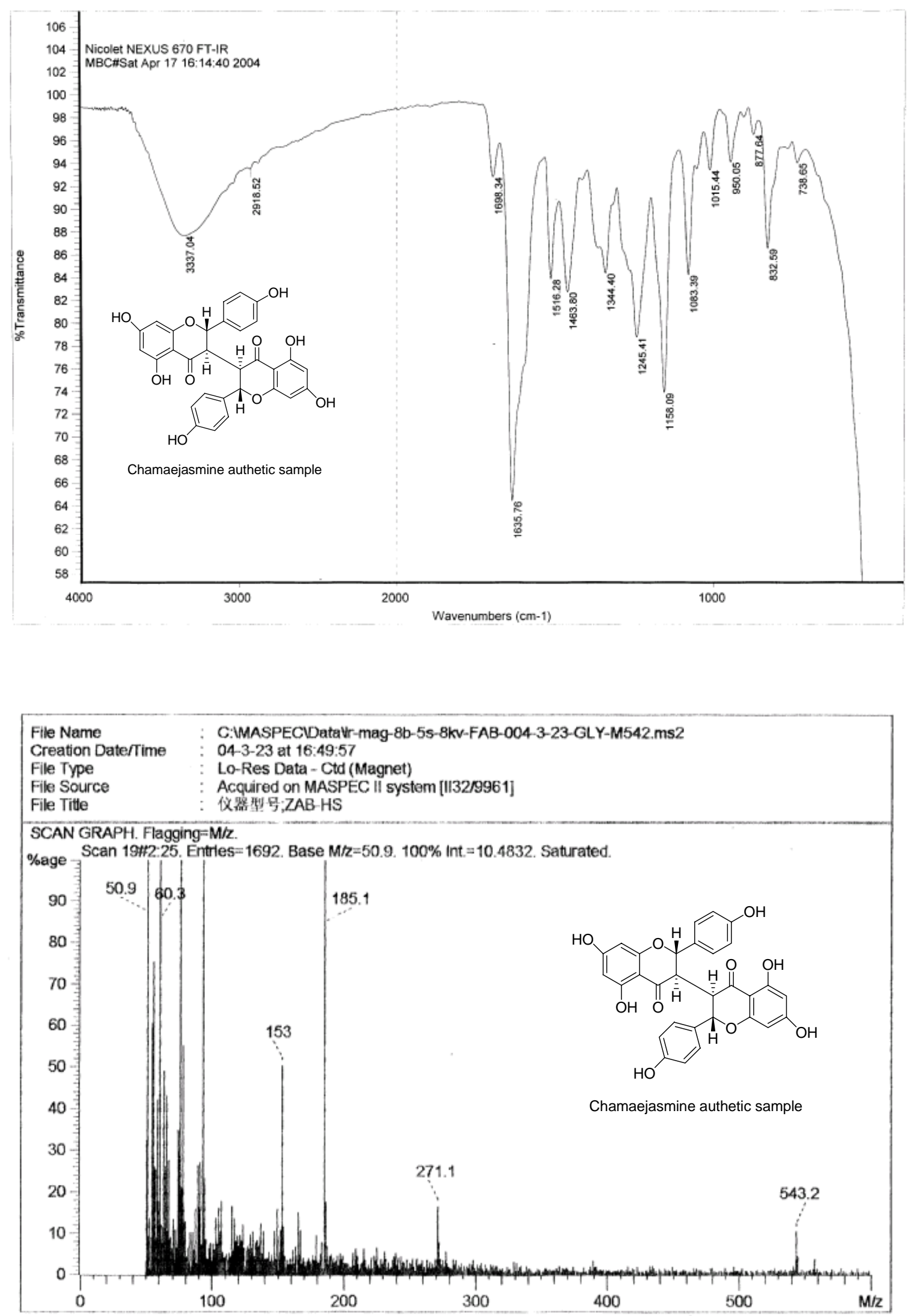


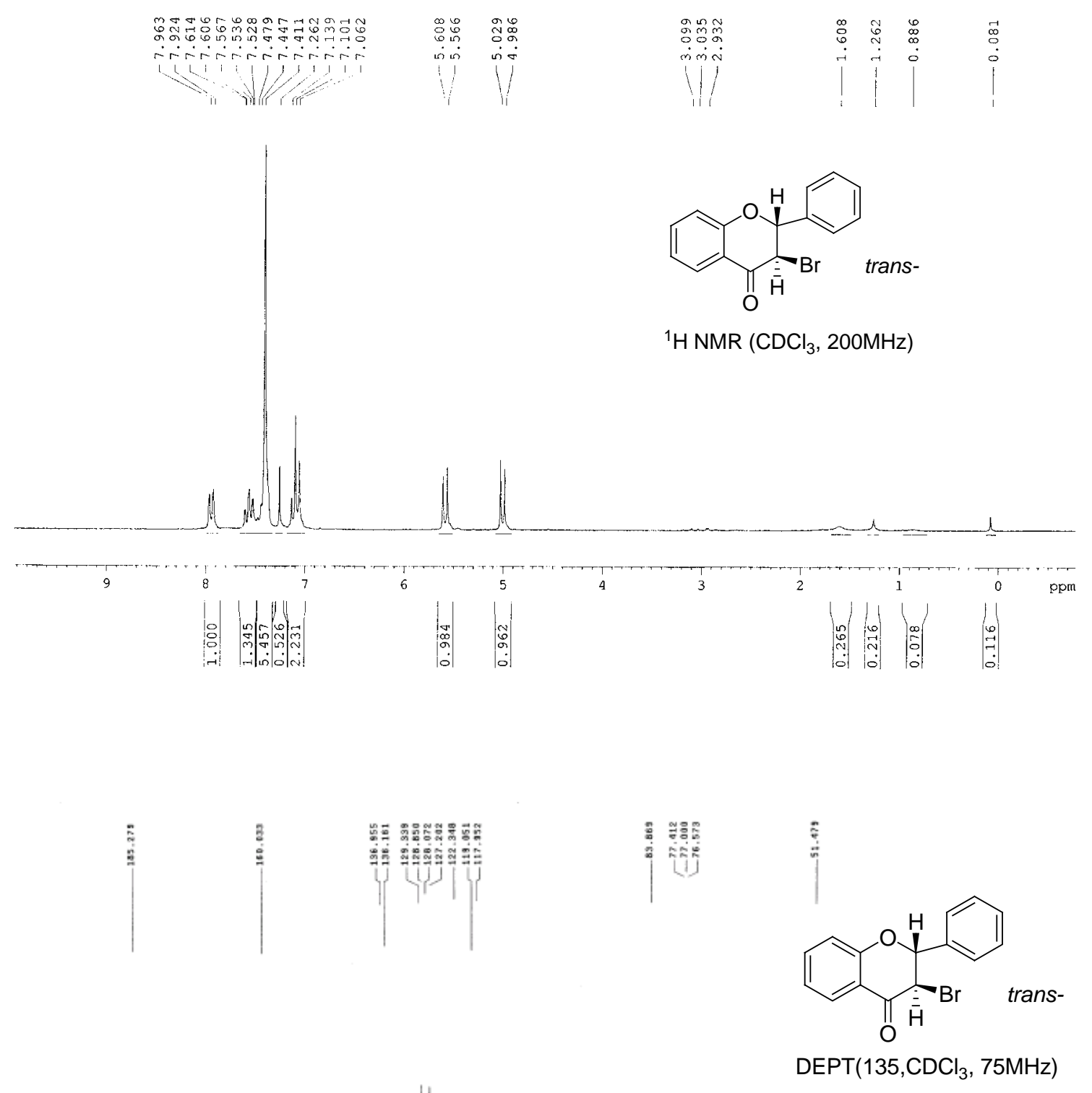

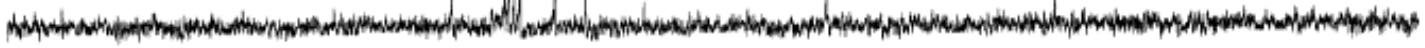

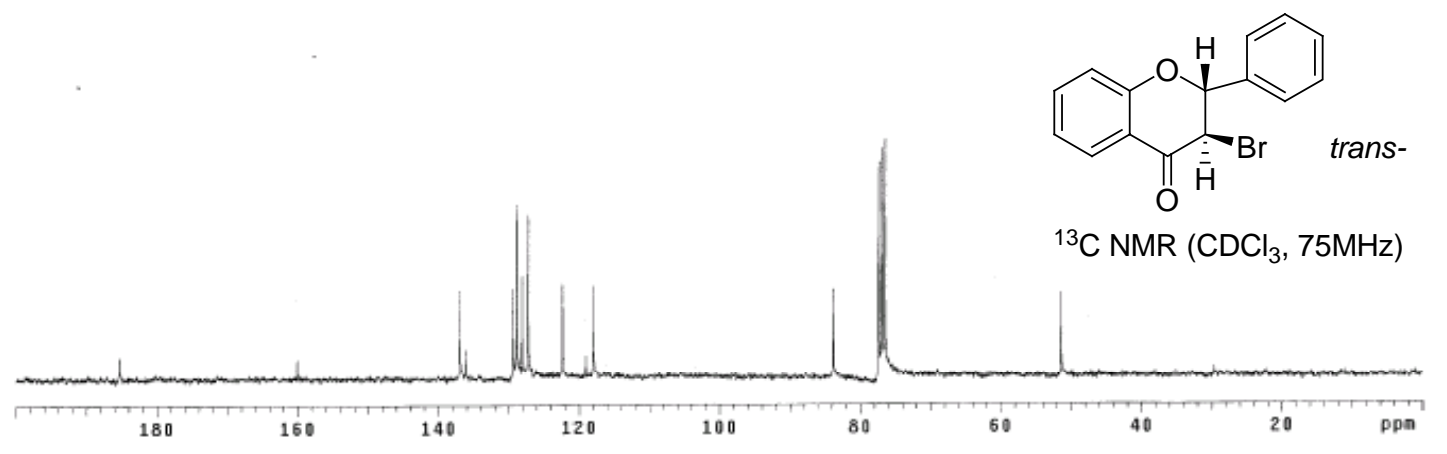




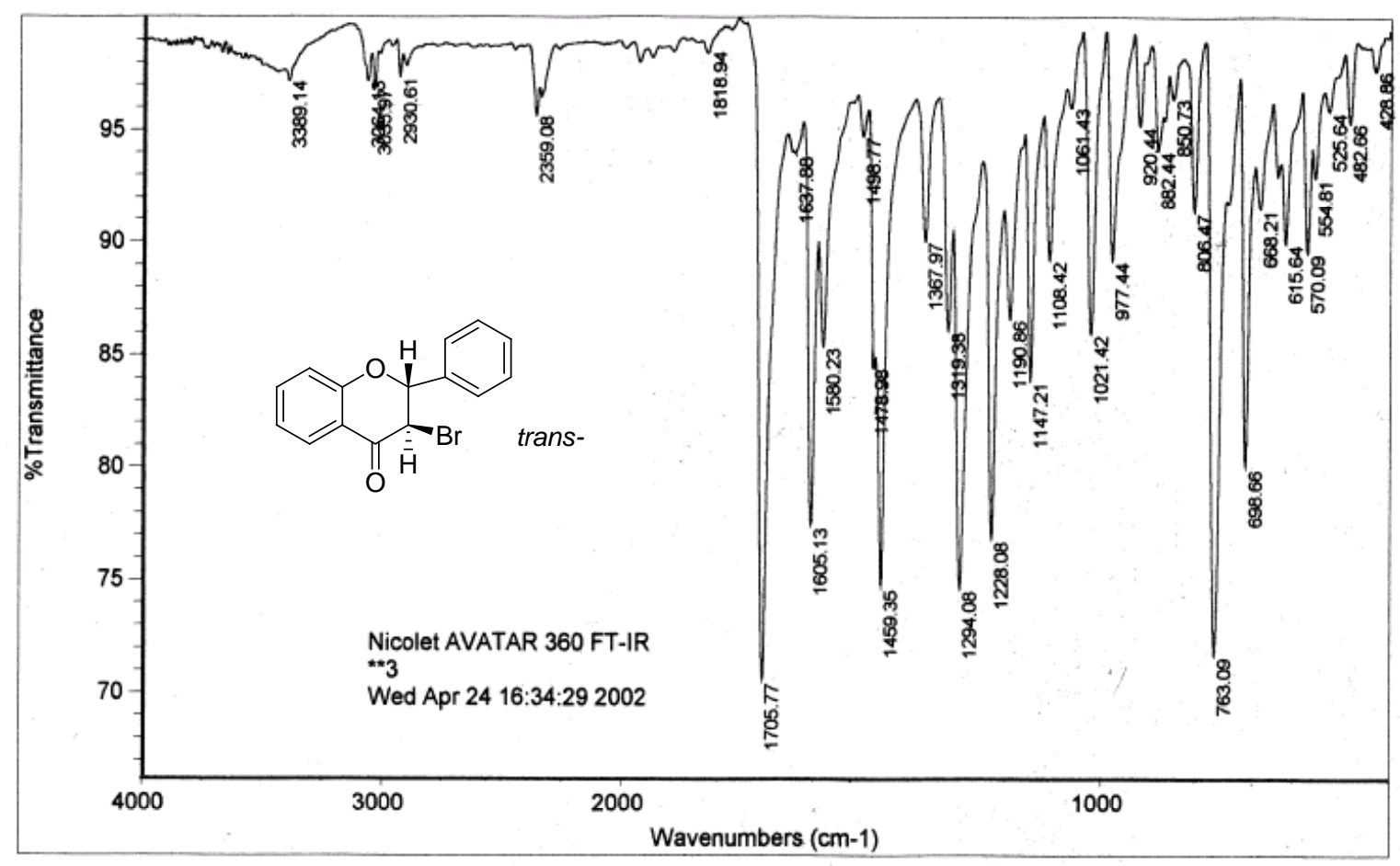

File : C: \HPCHEM $1 \backslash$ DATA $\backslash$ C1206.D

Operator : CQ, LZU NLAOC
Acquired : 11 Dec 2001 9:07 using AcqMethod DIP700

Instrument : HP 5988

Sample Name: MA BAD-CHUN, 302

Misc Info :

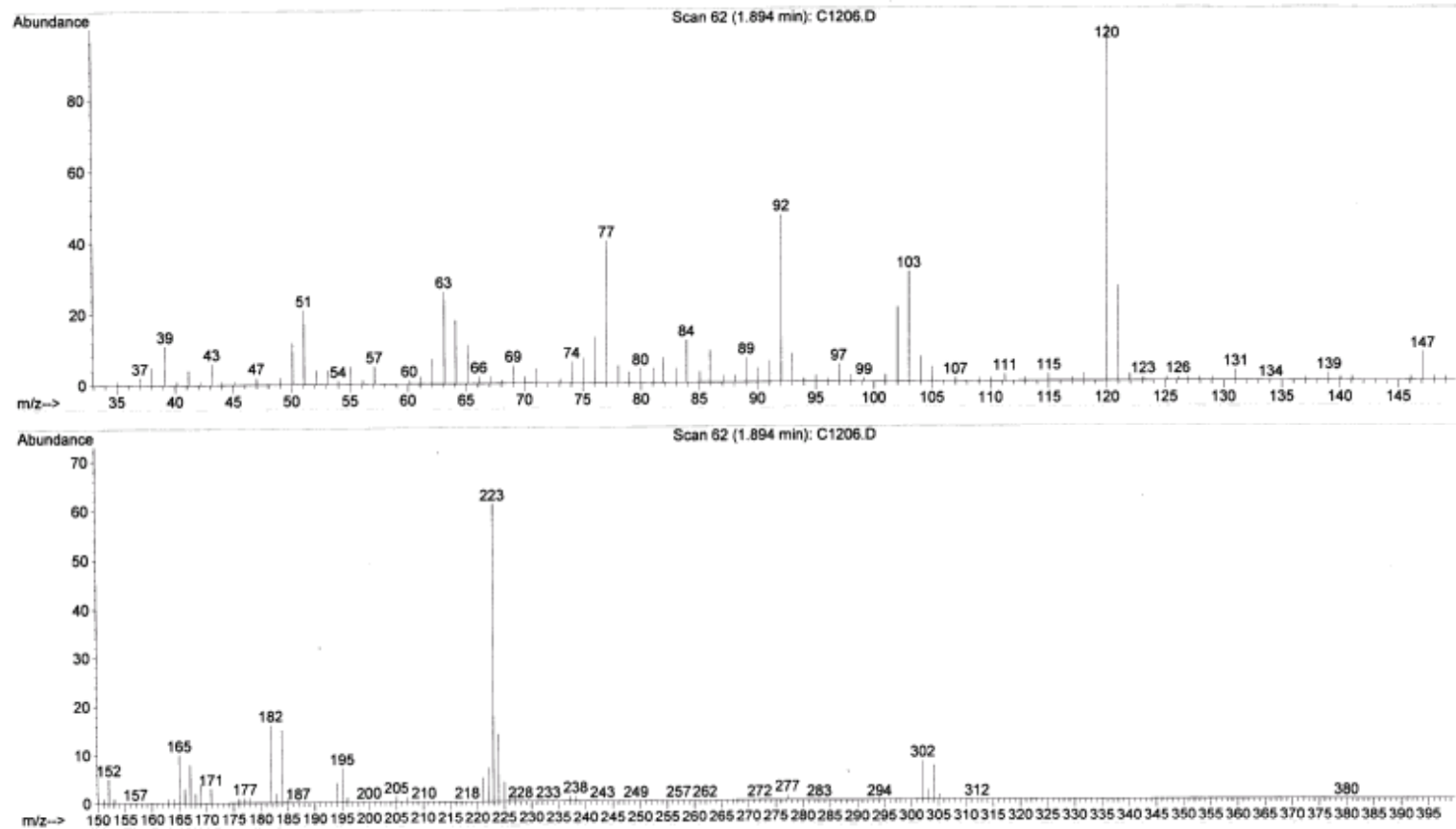



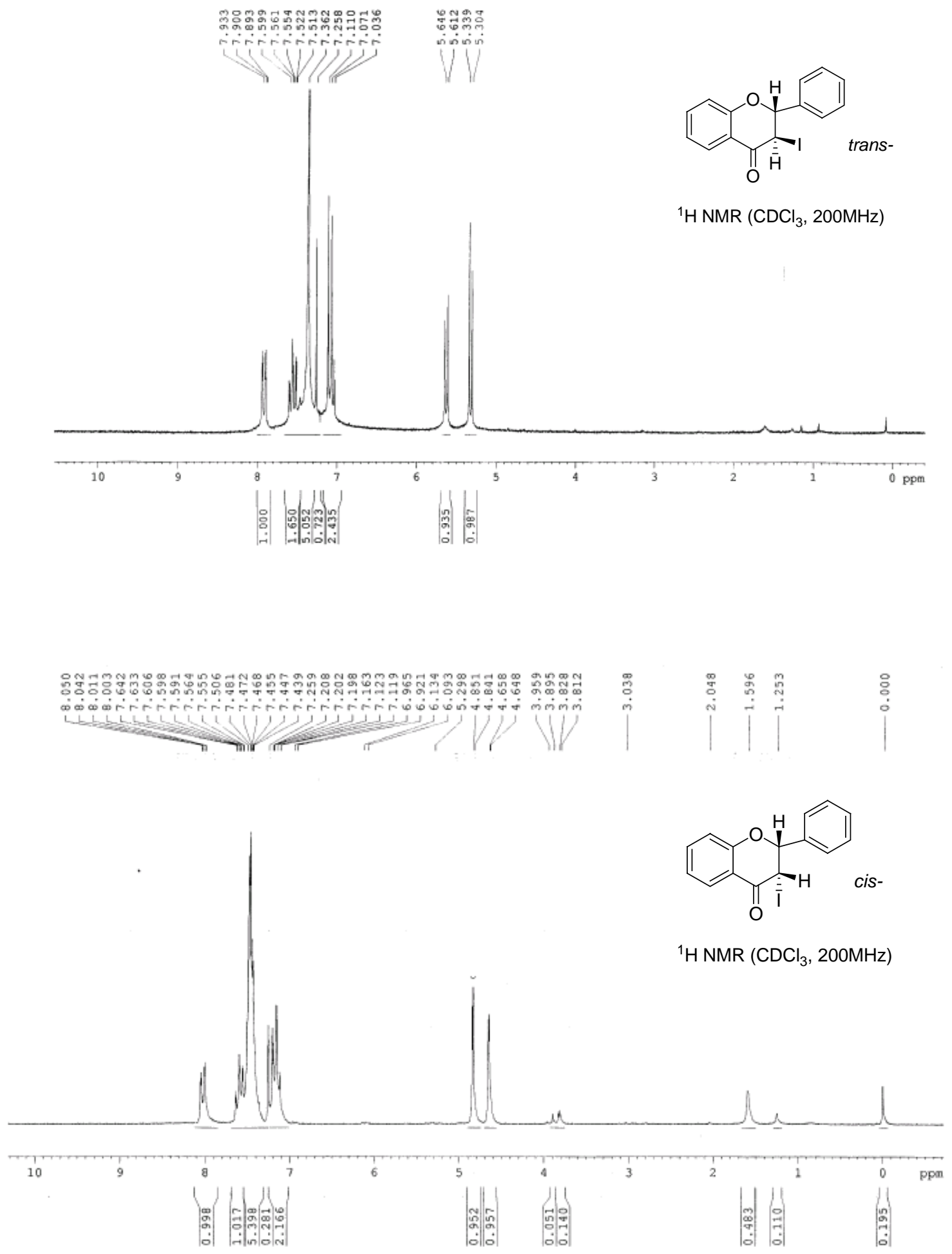


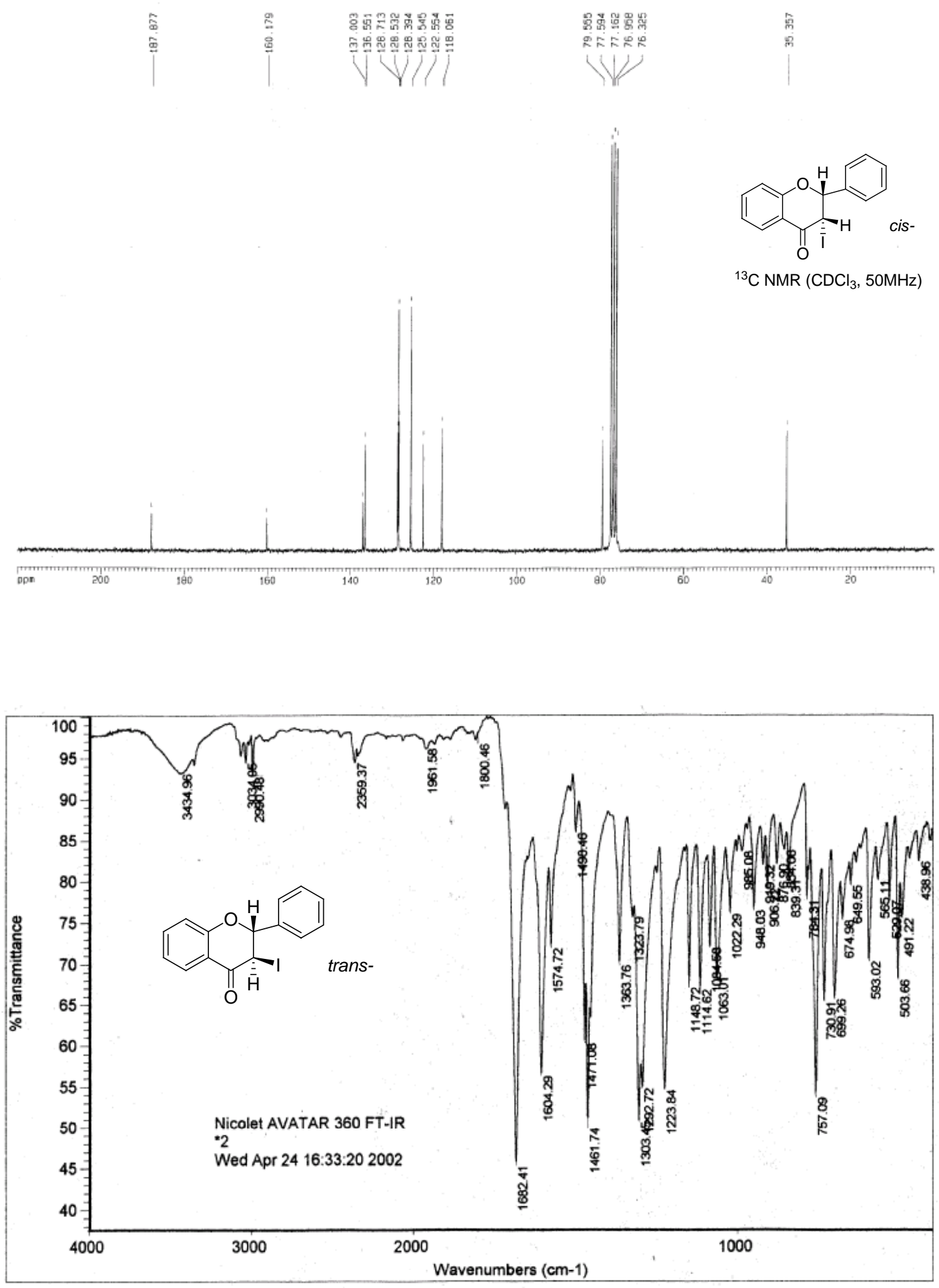




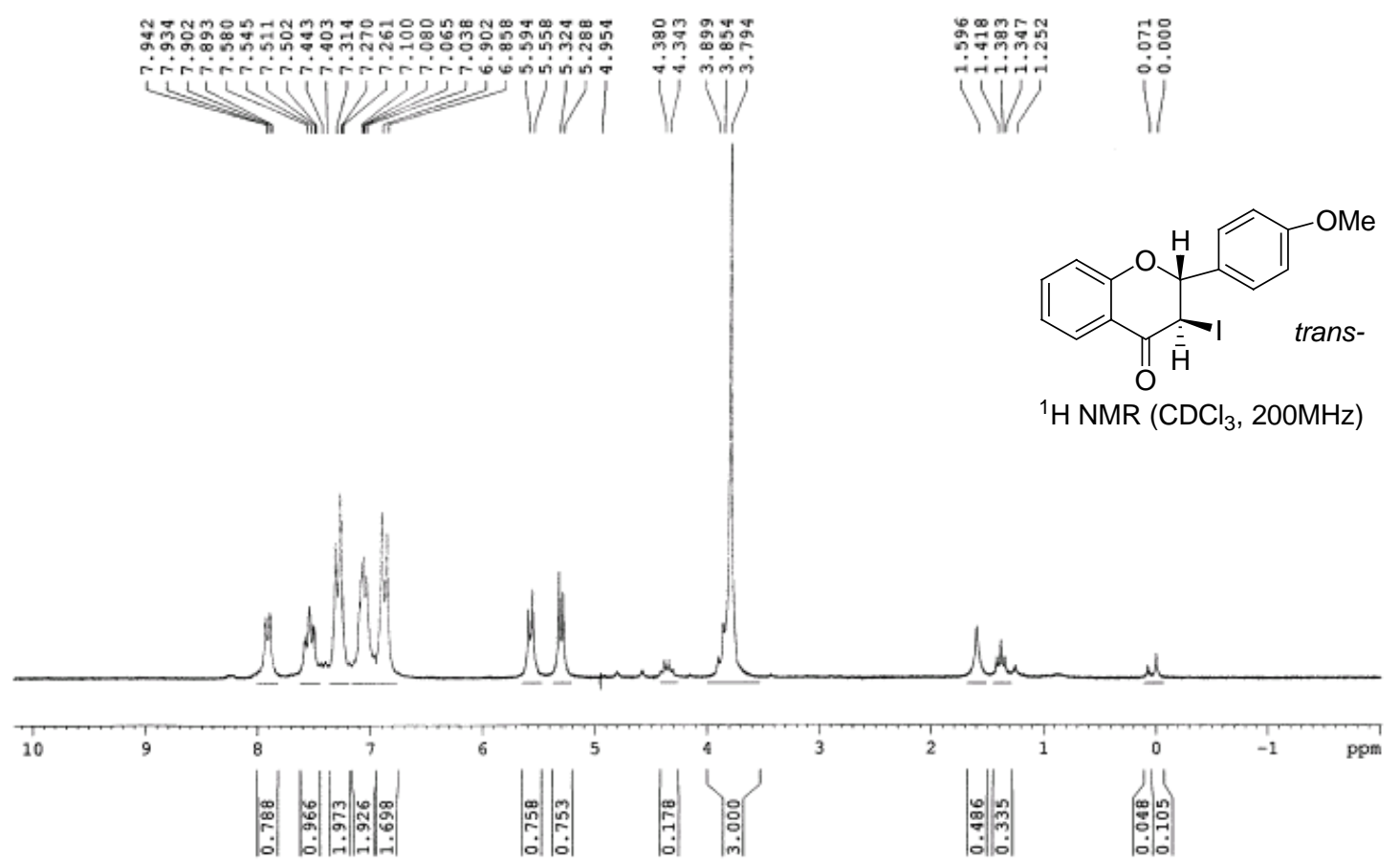

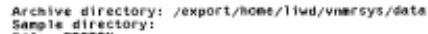

Sanple dirfectory

Puise sequencel s2pul

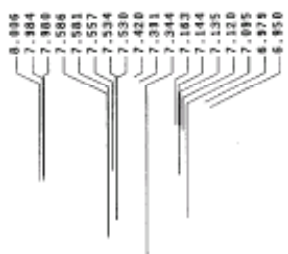

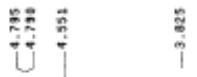

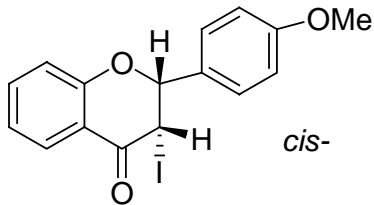

${ }^{1} \mathrm{H}$ NMR $\left(\mathrm{CDCl}_{3}, 300 \mathrm{MHz}\right)$

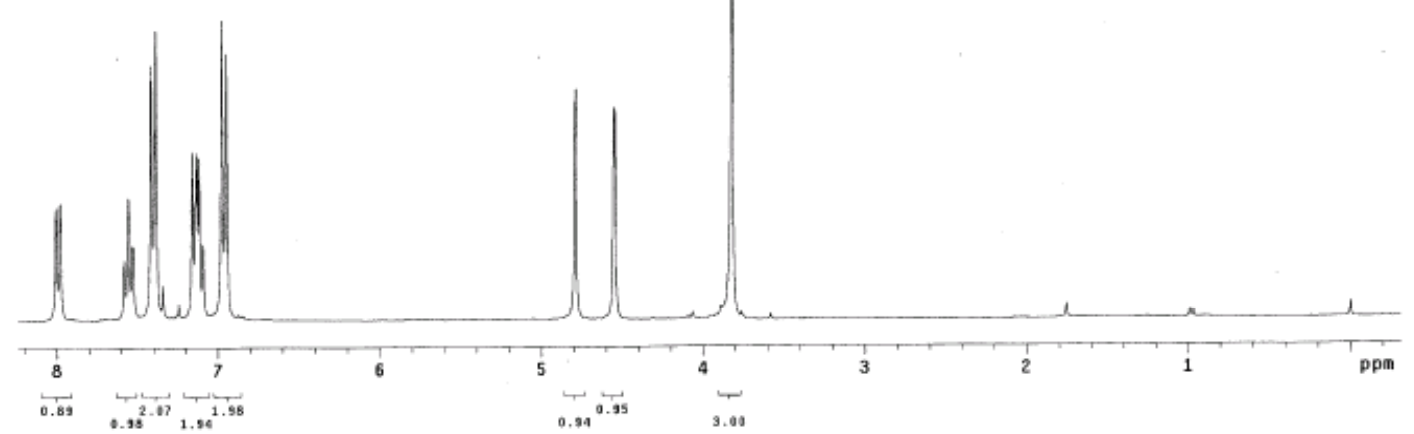


19C osstenve

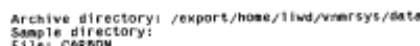

Fin: c carkon
ำ

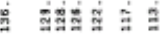

ij i i<smiles>COc1ccc([C@H]2Oc3ccccc3C(=O)[C@@H]2I)cc1</smiles>

DEPT(135, $\left.\mathrm{CDCl}_{3}, 75 \mathrm{MHz}\right)$

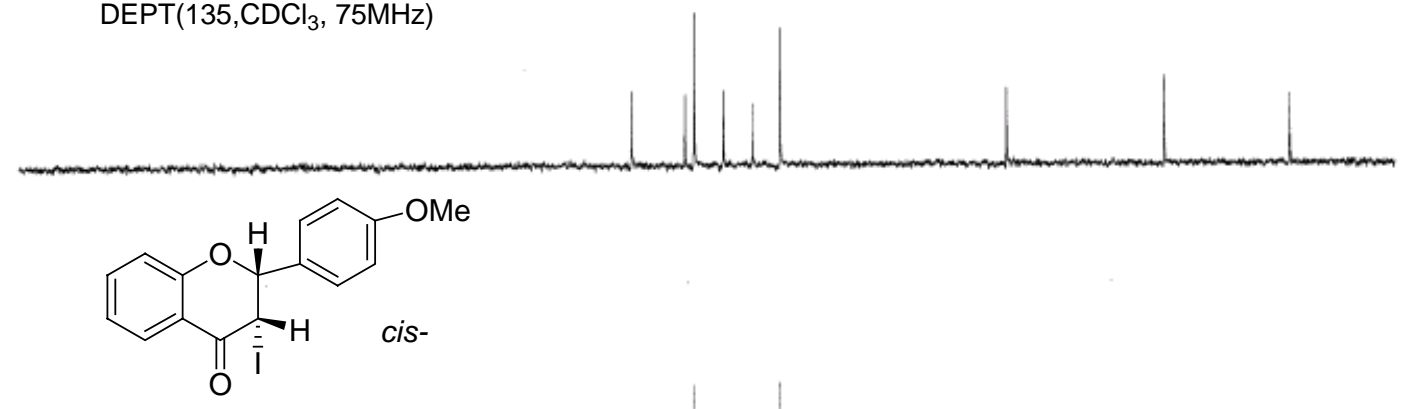

${ }^{13} \mathrm{C}$ NMR $\left(\mathrm{CDCl}_{3}, 75 \mathrm{MHz}\right)$

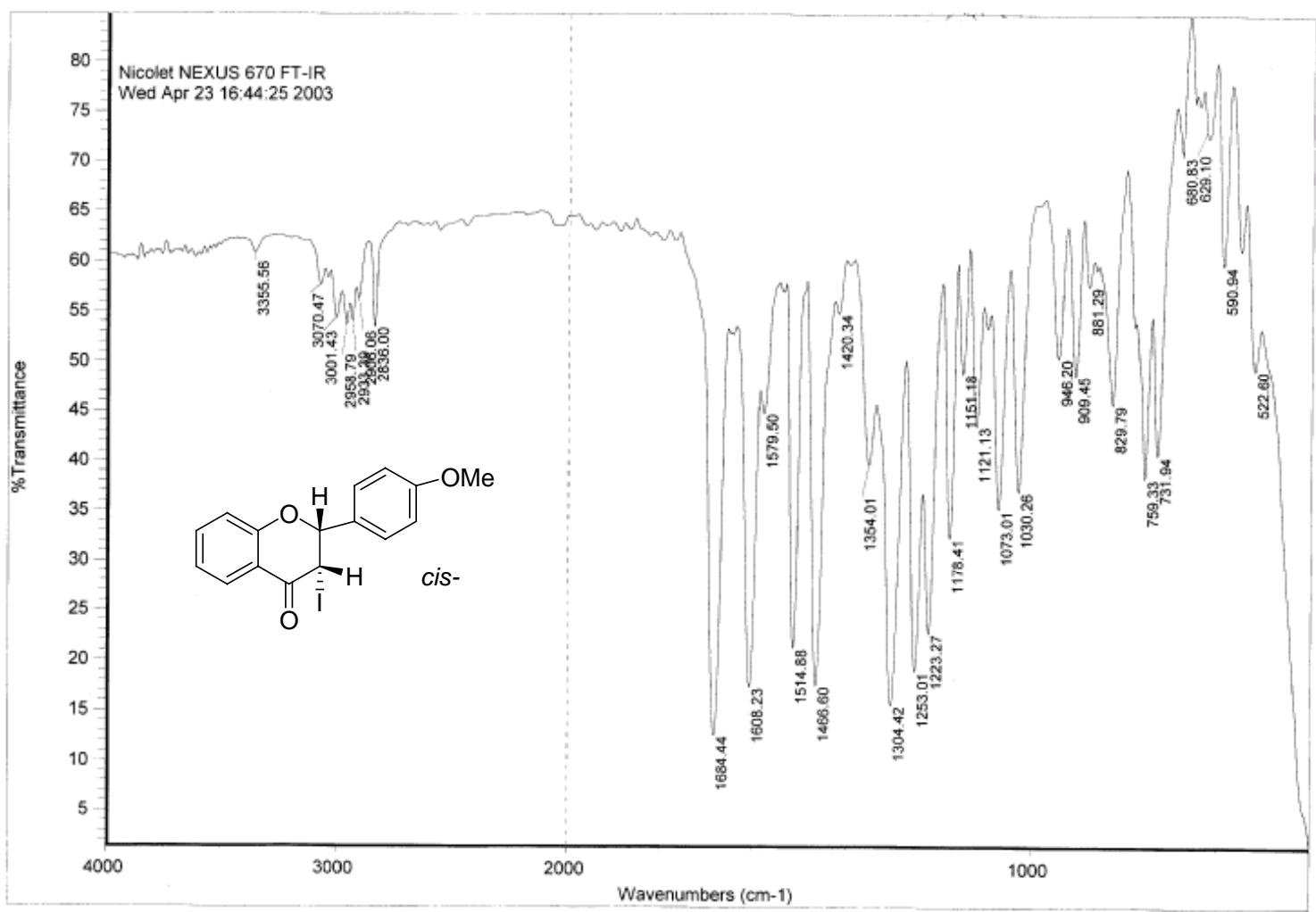




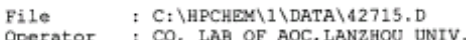

Operator : CQ, LAB OF AOC, LANZHOU UNIV.
Acquired : 27 Apr $200210: 17$ using AcqMethod DIP700

AP 5988

Sample Name: MA ВAD̄-CHUN, 270/3BO

vial Number:
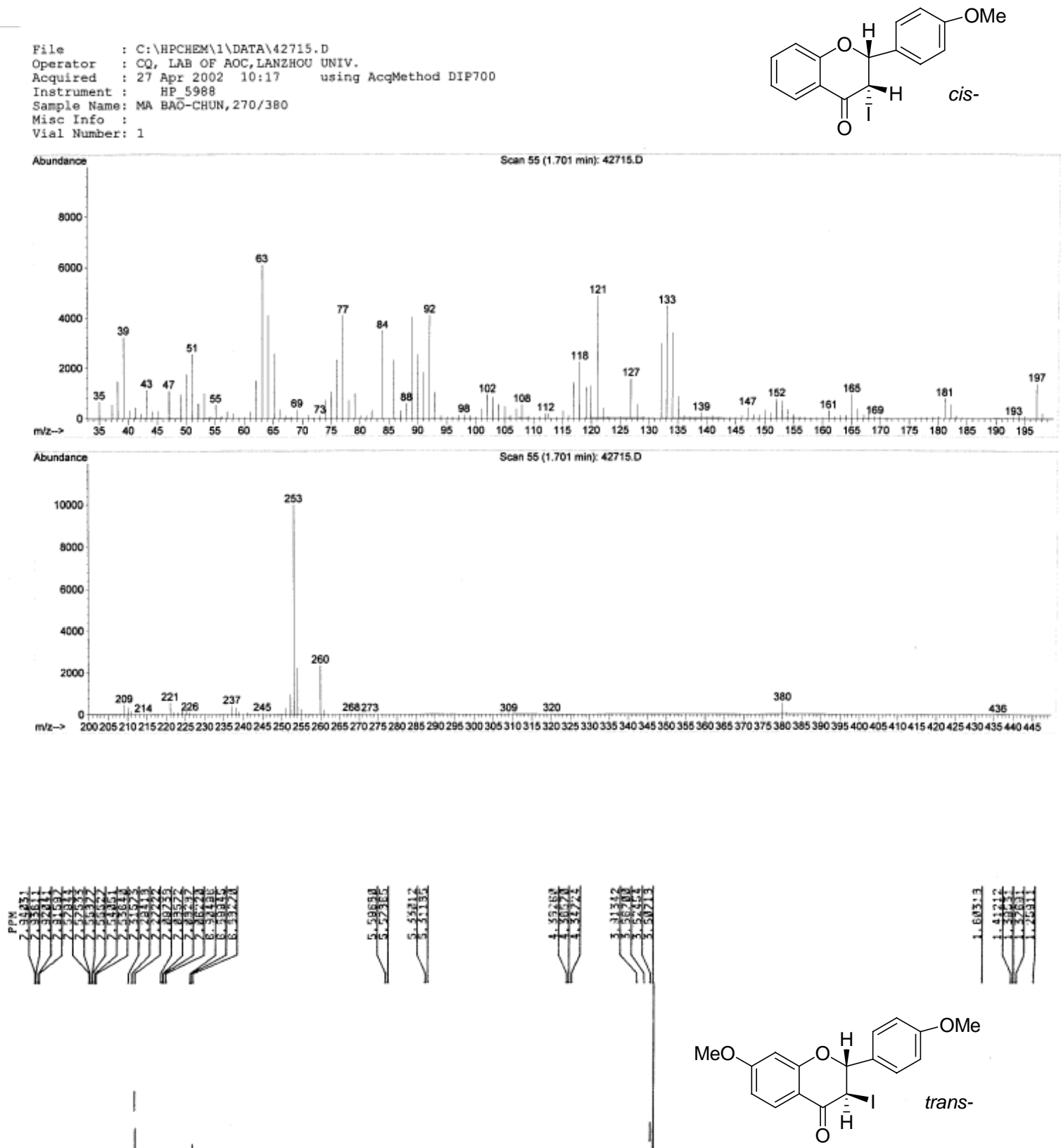

${ }^{1} \mathrm{H} \mathrm{NMR}\left(\mathrm{CDCl}_{3}, 400 \mathrm{MHz}\right)$

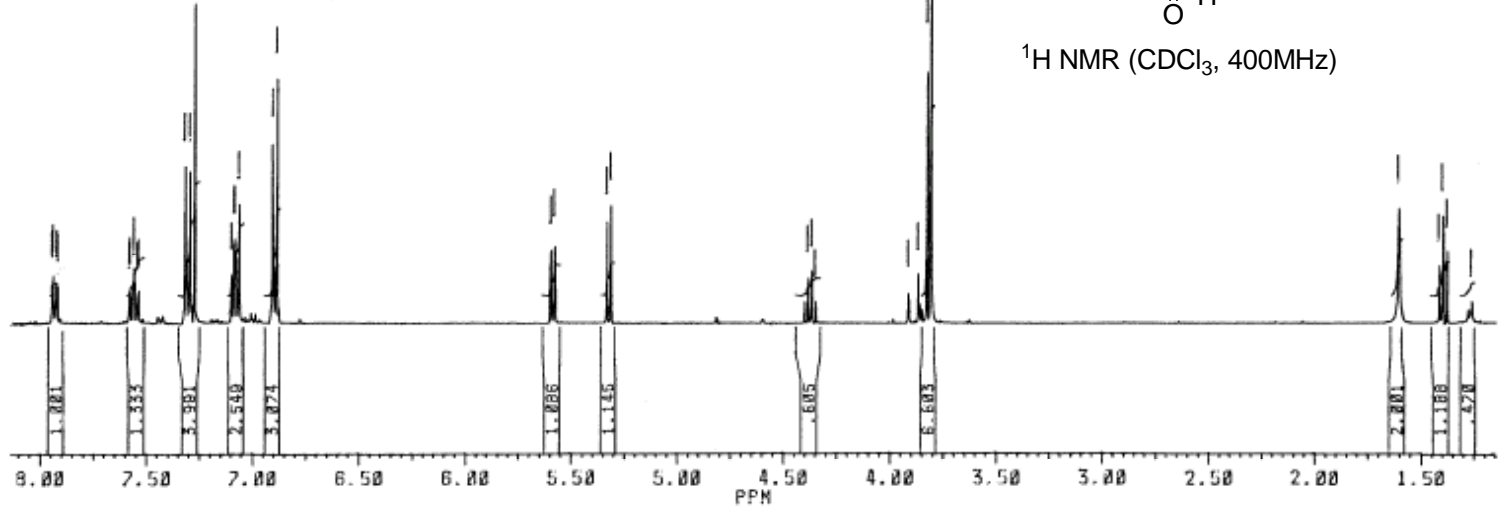




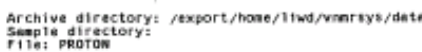

Pulse sequencel szeut
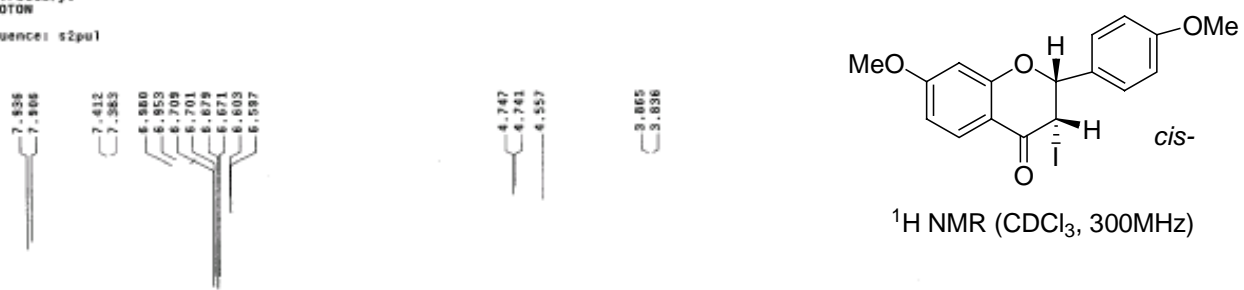

${ }^{1} \mathrm{H} \operatorname{NMR}\left(\mathrm{CDCl}_{3}, 300 \mathrm{MHz}\right)$

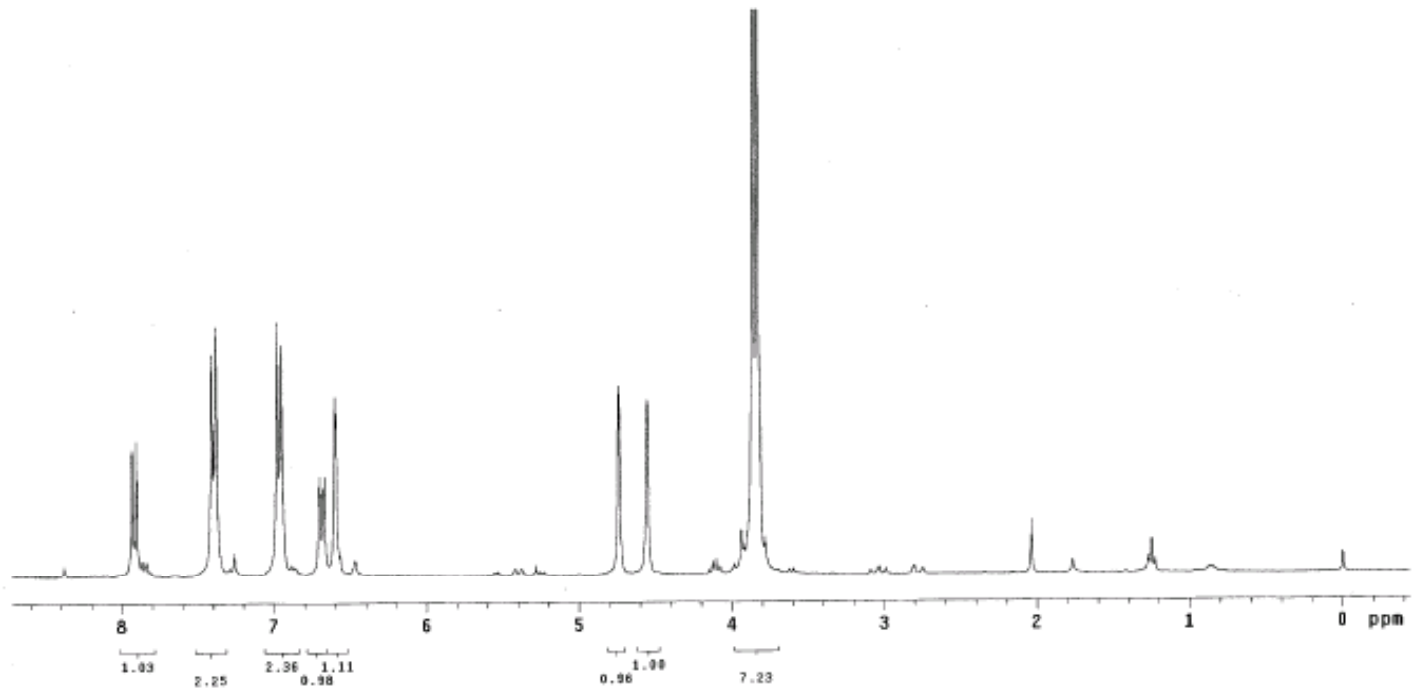

13c oвstenve

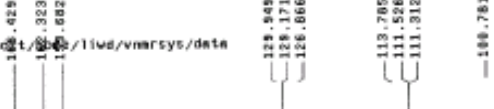

มุด

[iิ
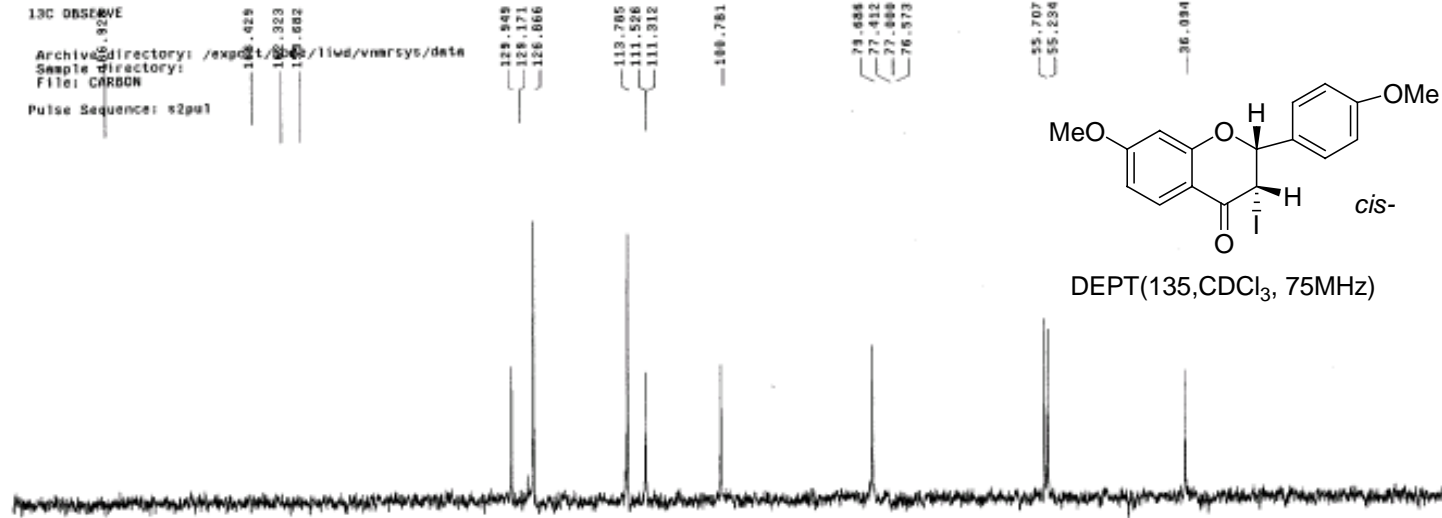

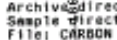

Pulse Sequencer 52 pul

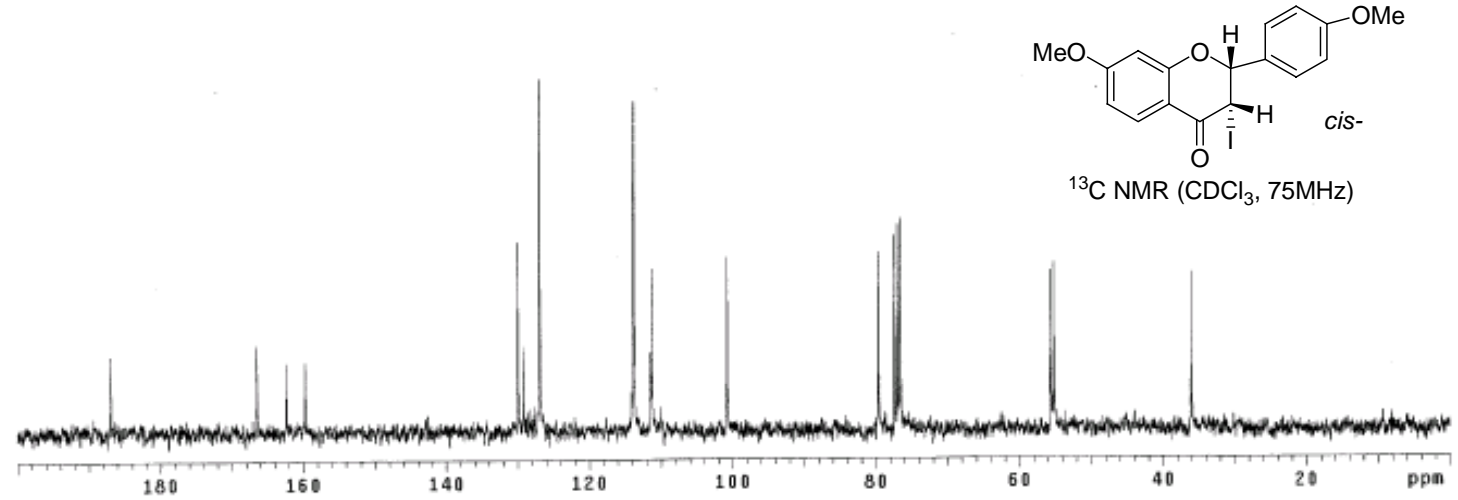

${ }^{13} \mathrm{C}$ NMR $\left(\mathrm{CDCl}_{3}, 75 \mathrm{MHz}\right)$ 

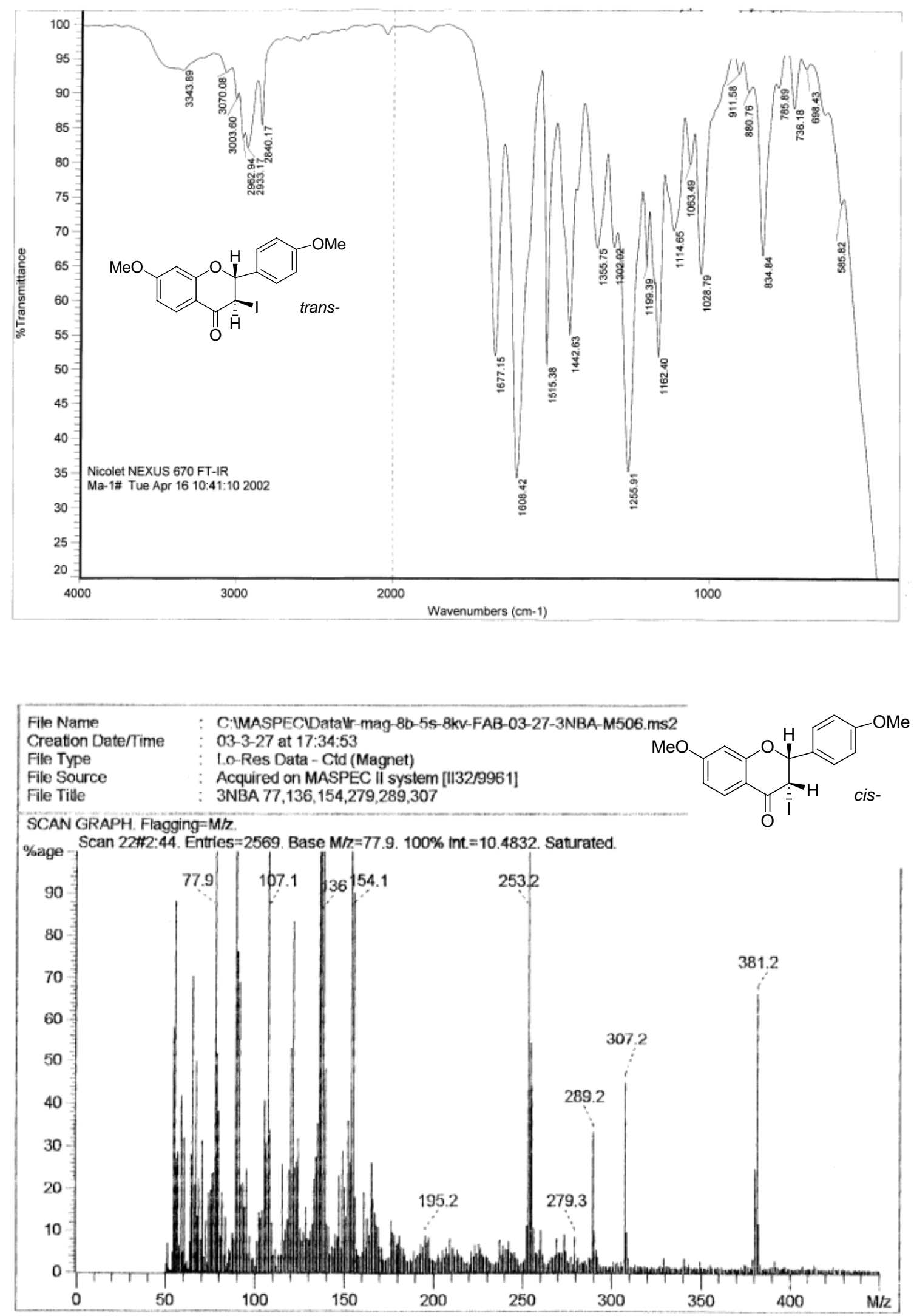


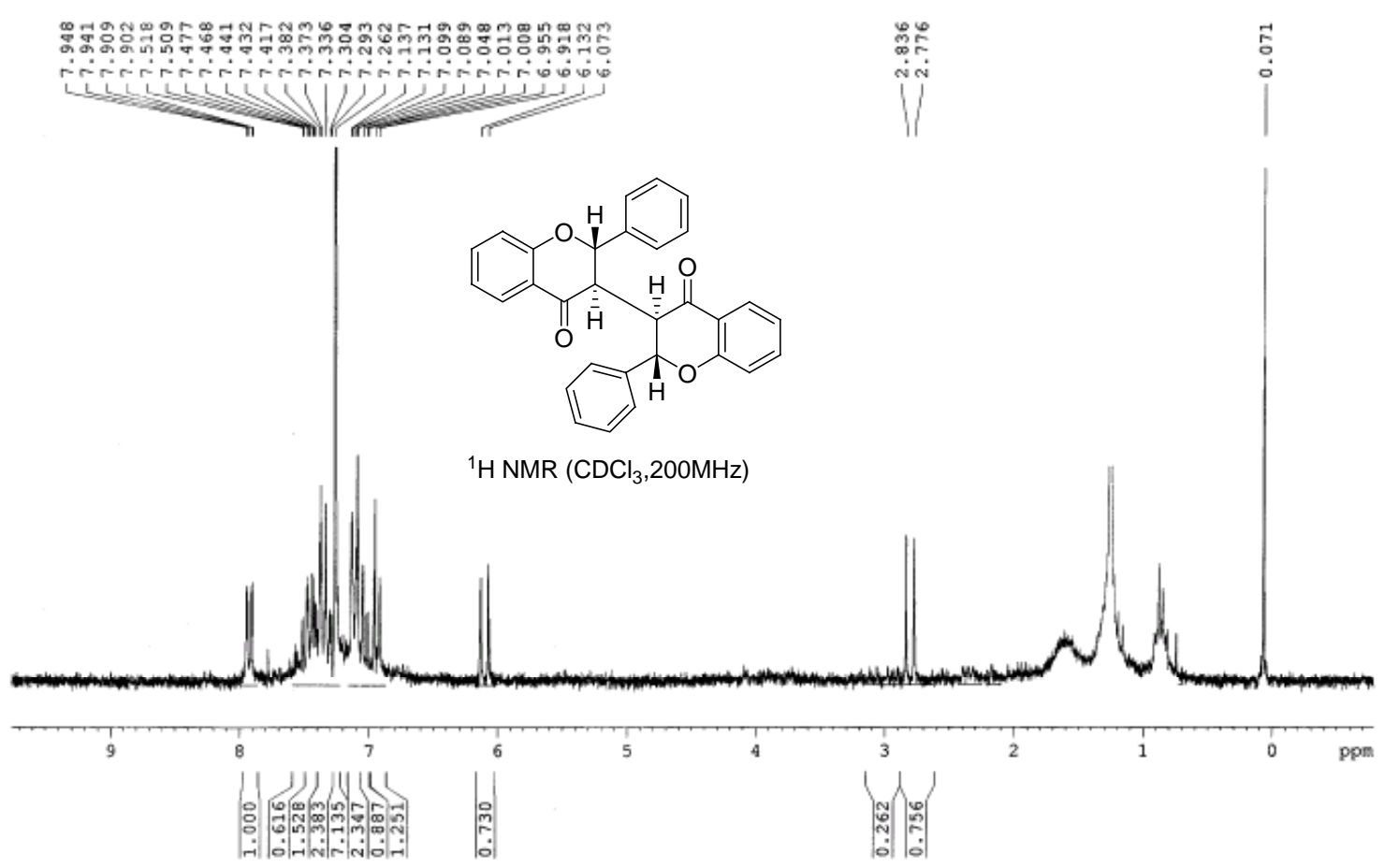

moc

Archive directory: /export/none/liwd/vmareys/data

Shaple dilfectory:
Puls:
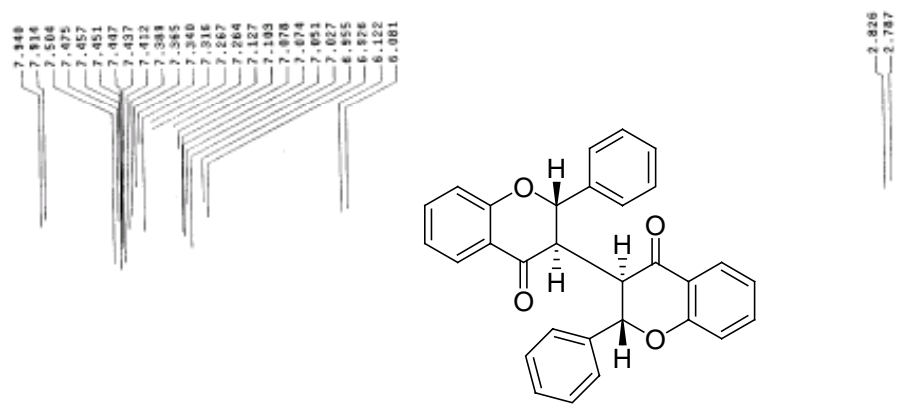

$\mathrm{H}$ NMR $\left(\mathrm{CDCl}_{3}, 300 \mathrm{MHz}\right)$

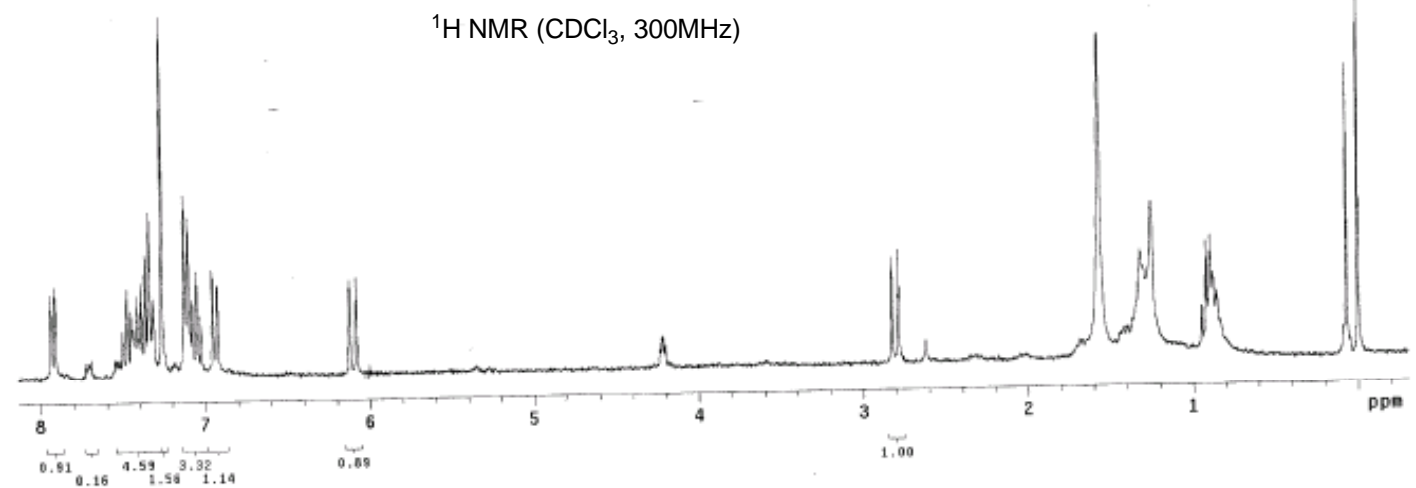



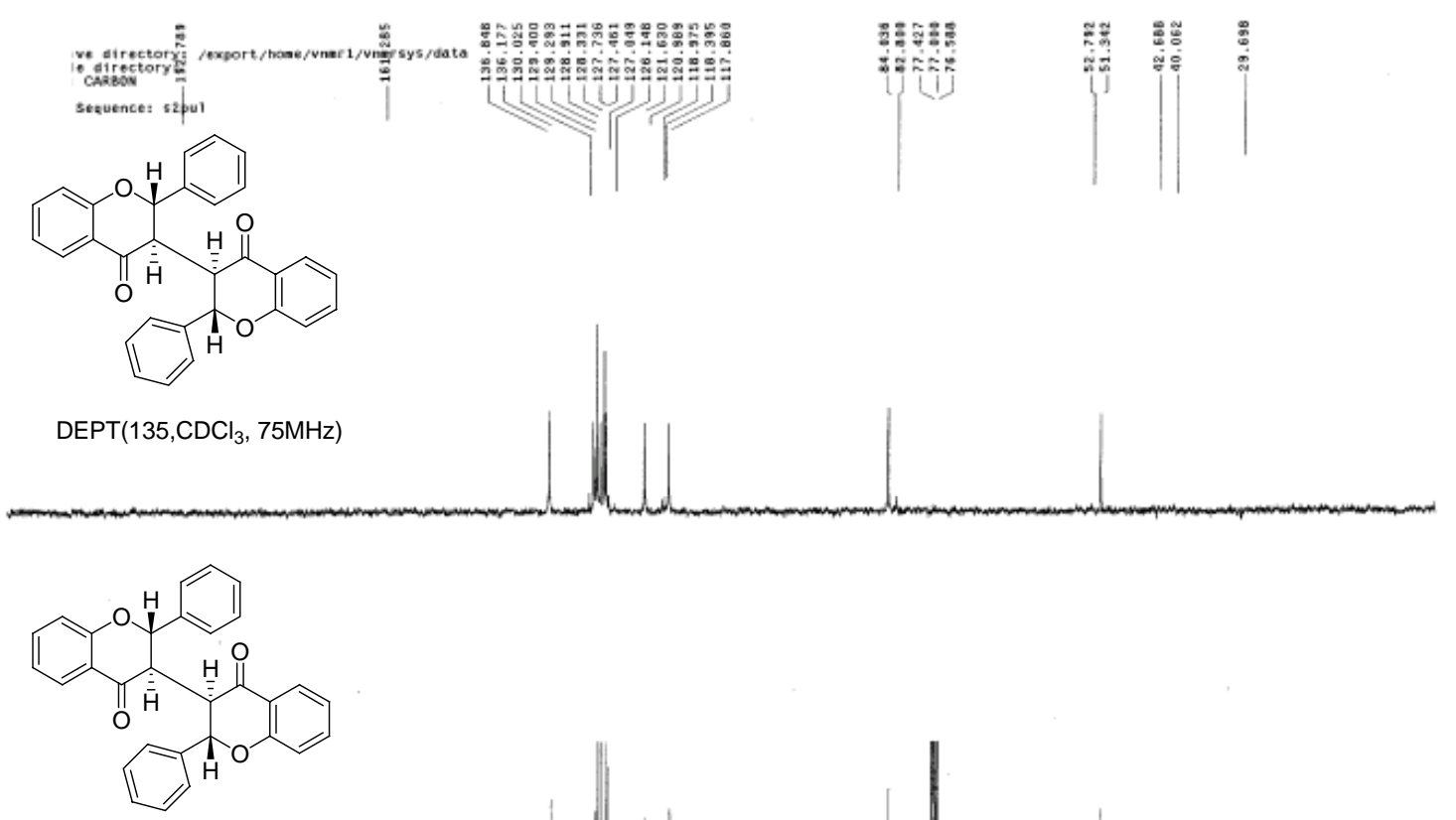

${ }^{13} \mathrm{C}$ NMR $\left(\mathrm{CDCl}_{3}, 75 \mathrm{MHz}\right)$
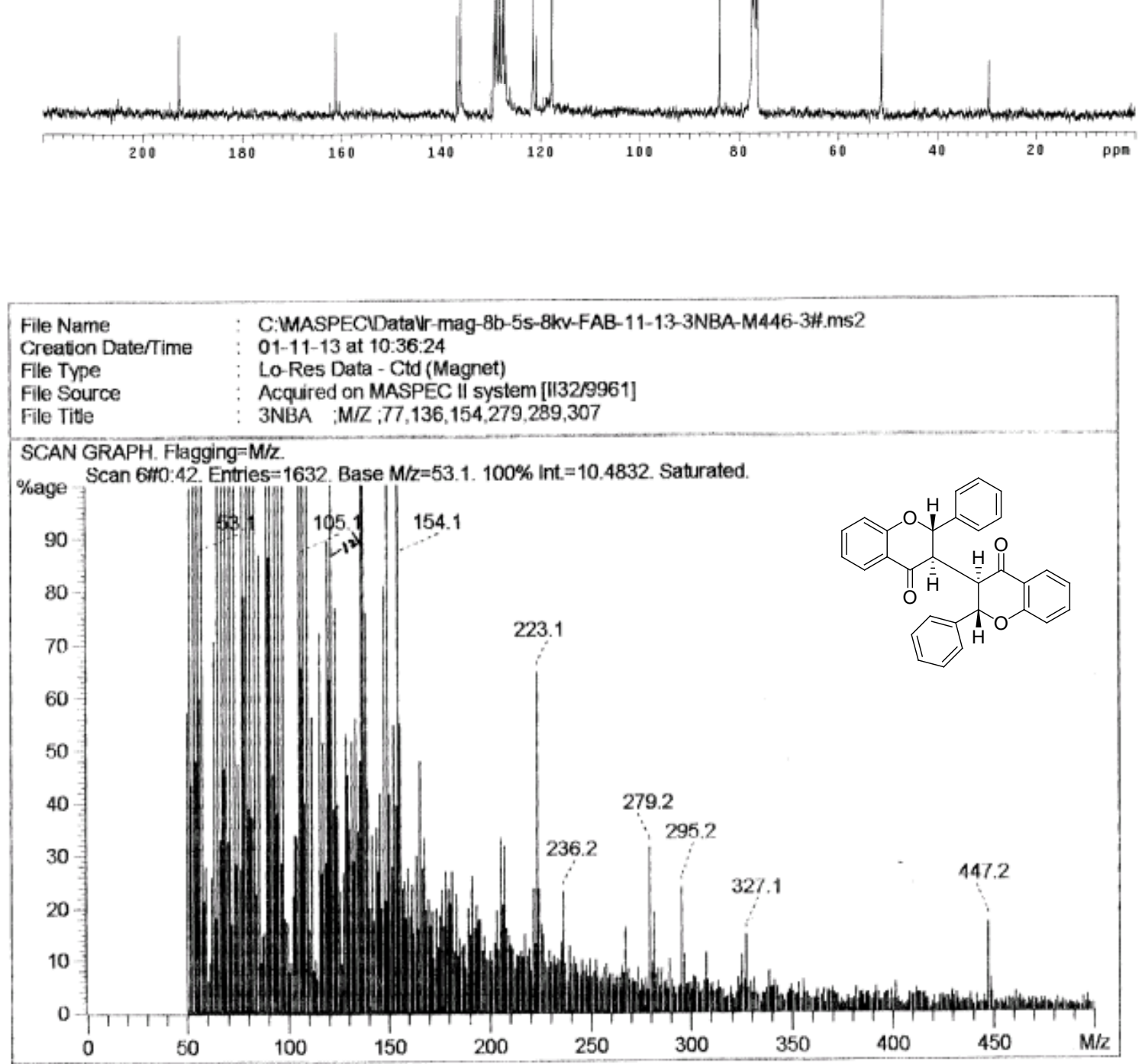

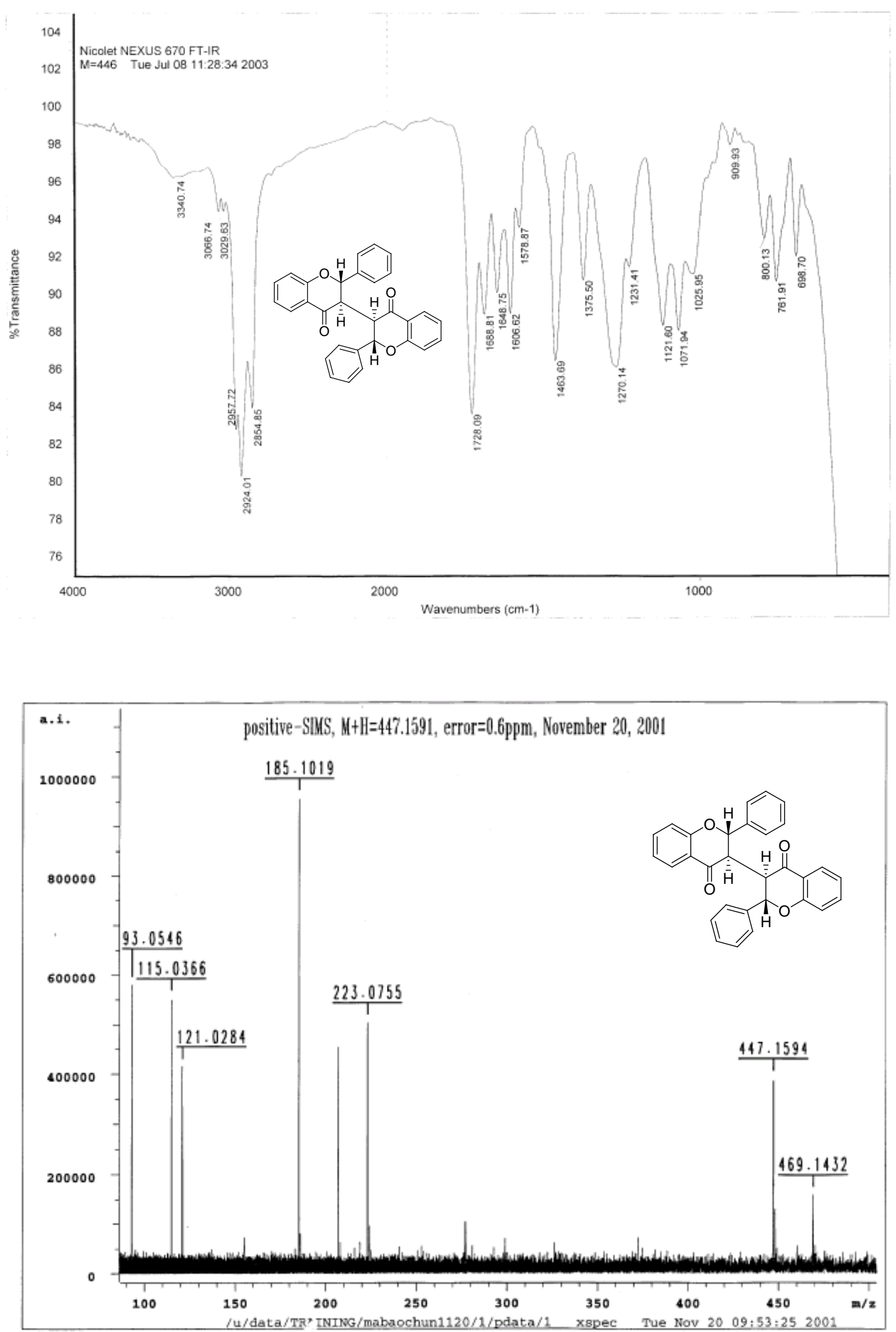

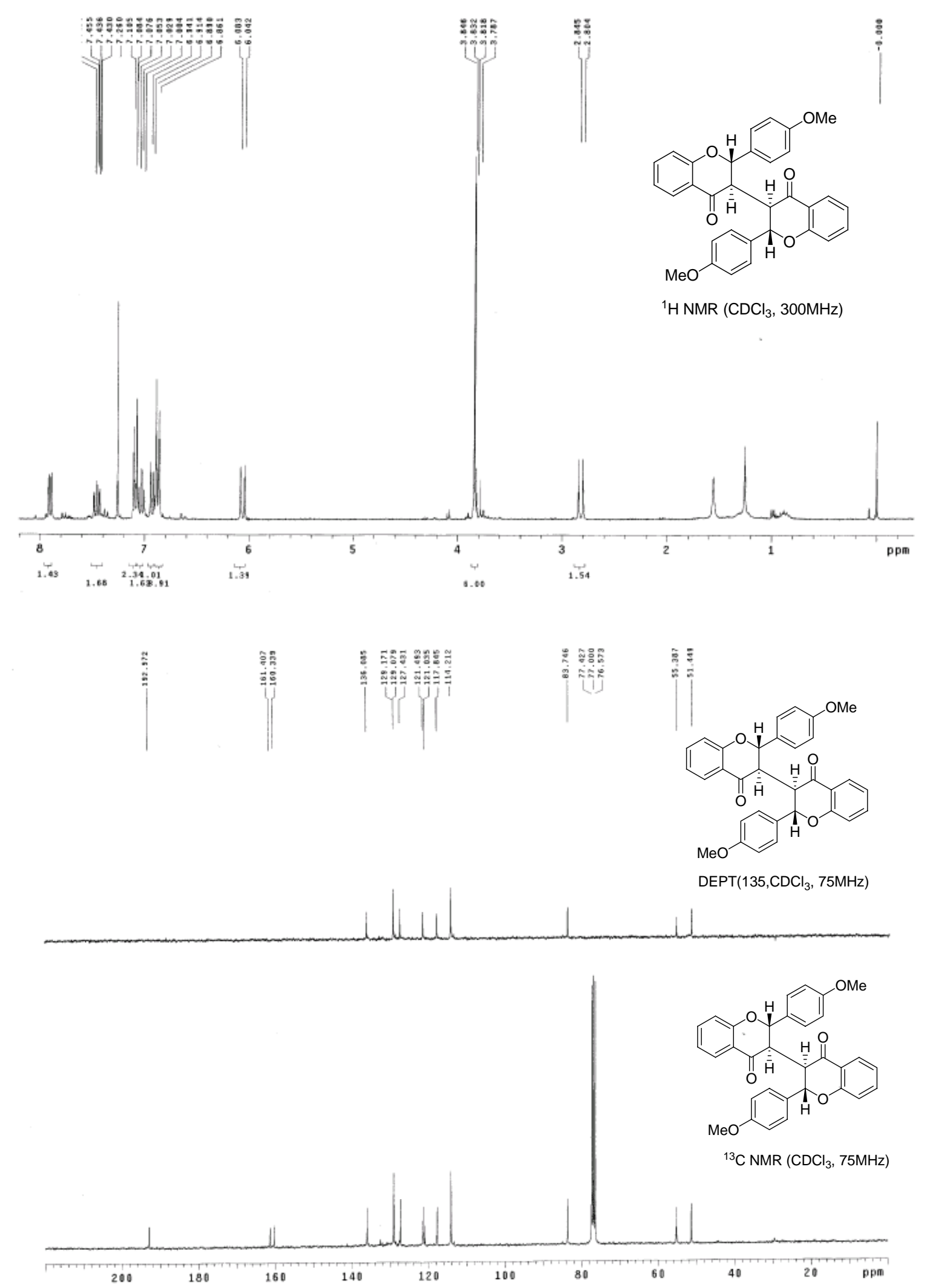


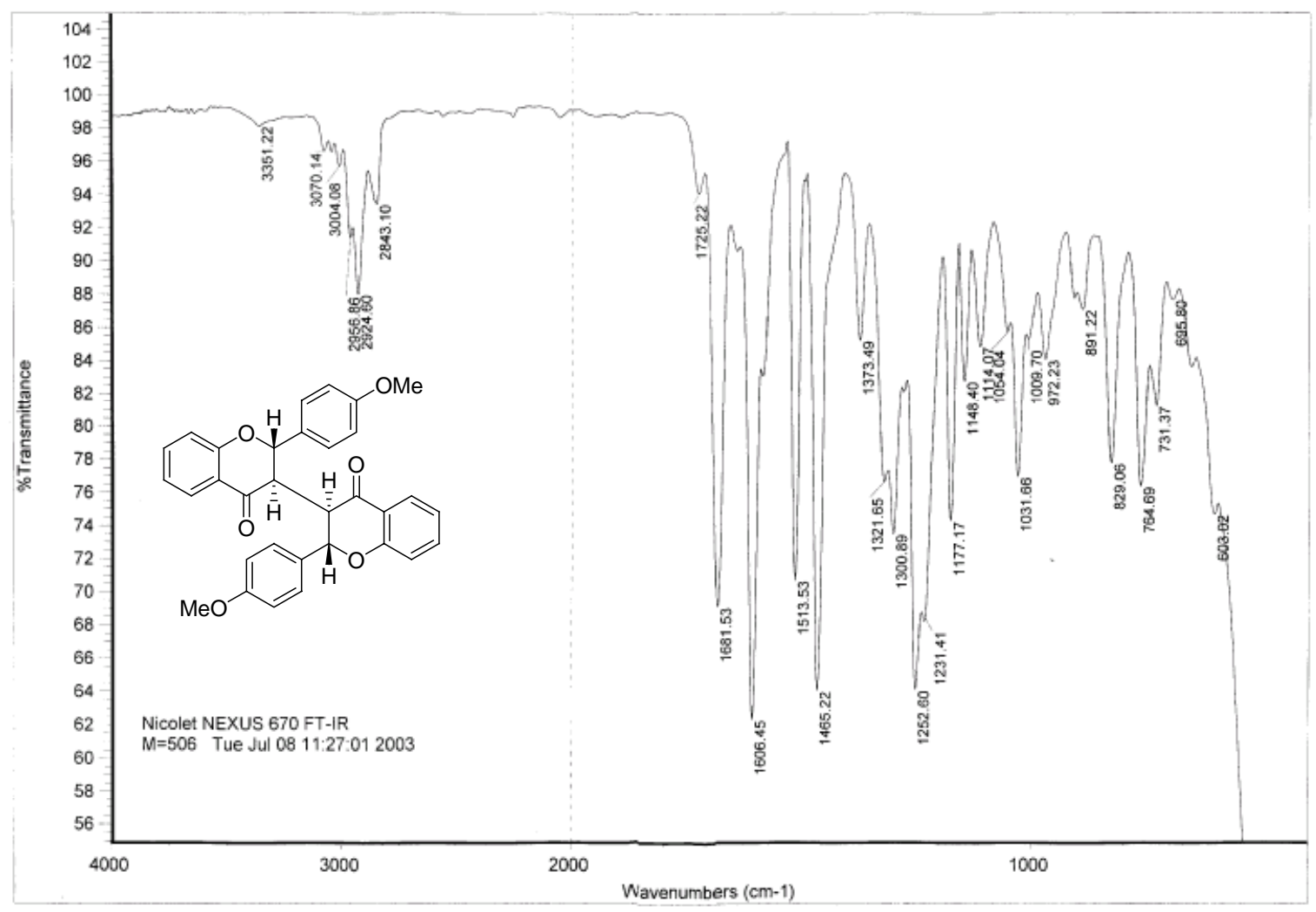

File

C: \HPCHEM $1 \backslash$ DATA $50712 . D$

Operator : HP598BA MS, Lanzhou University

Asing Aequethod DIP700

$\mathrm{HP} 5988$

Misc Info: National Lab of Applied Organic Chemistry

Vial Number:

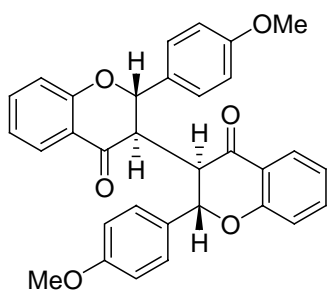

Abund

Average of 3.228 to $3.430 \mathrm{~min}: 50712 \mathrm{O}$

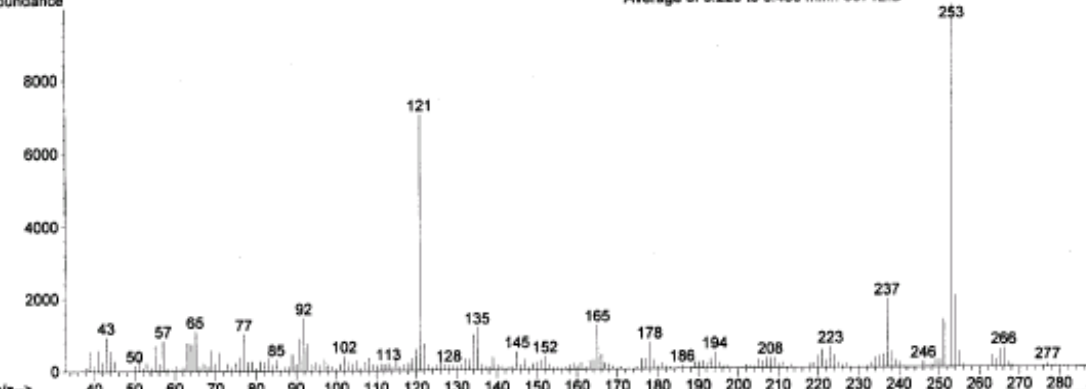

$\begin{array}{llll}313 & 329 & 343 & 357\end{array}$

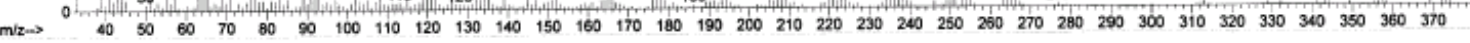

Abundarce $\quad$ Average of 3.228 to $3.430 \mathrm{~min}: 50712.0$

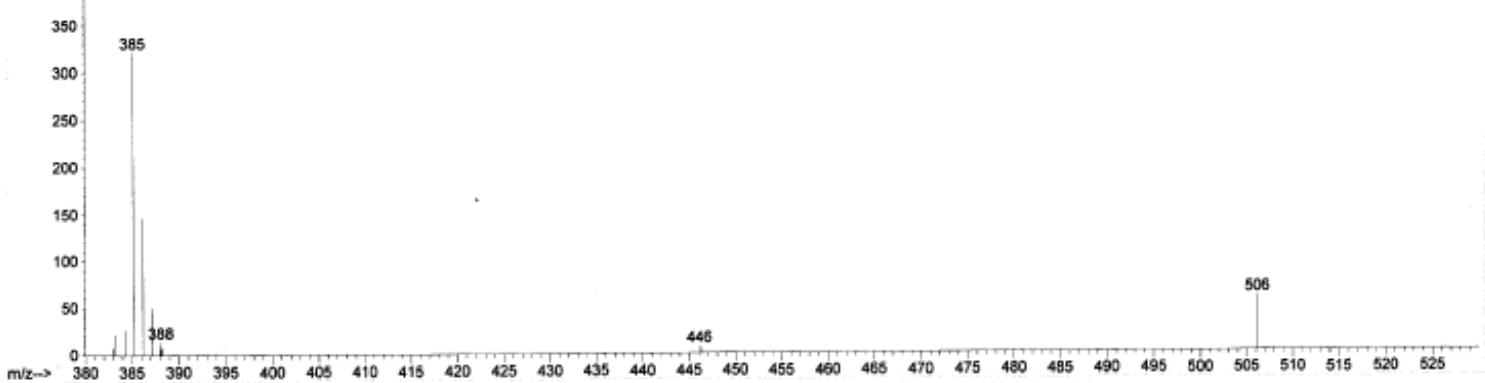



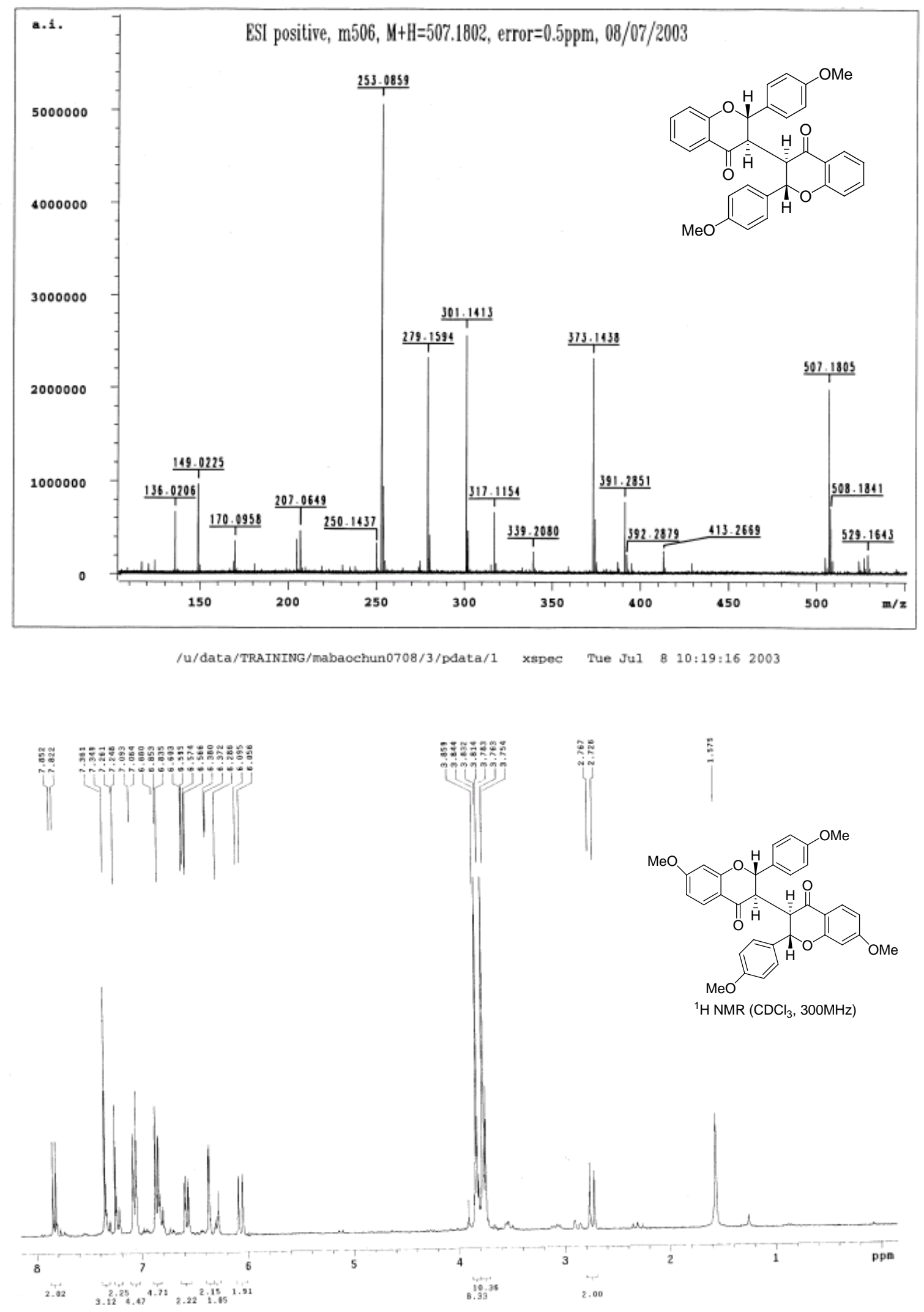

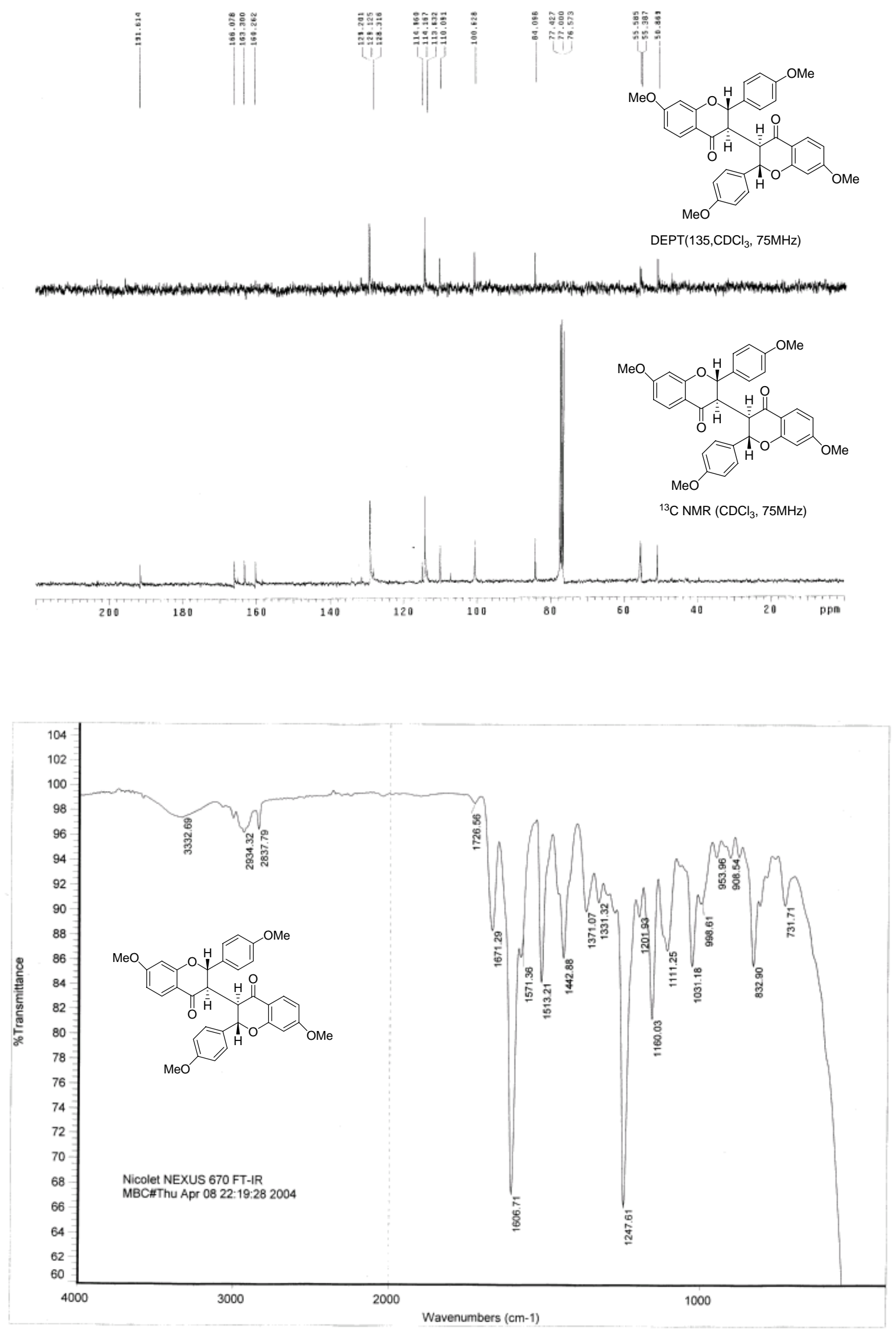

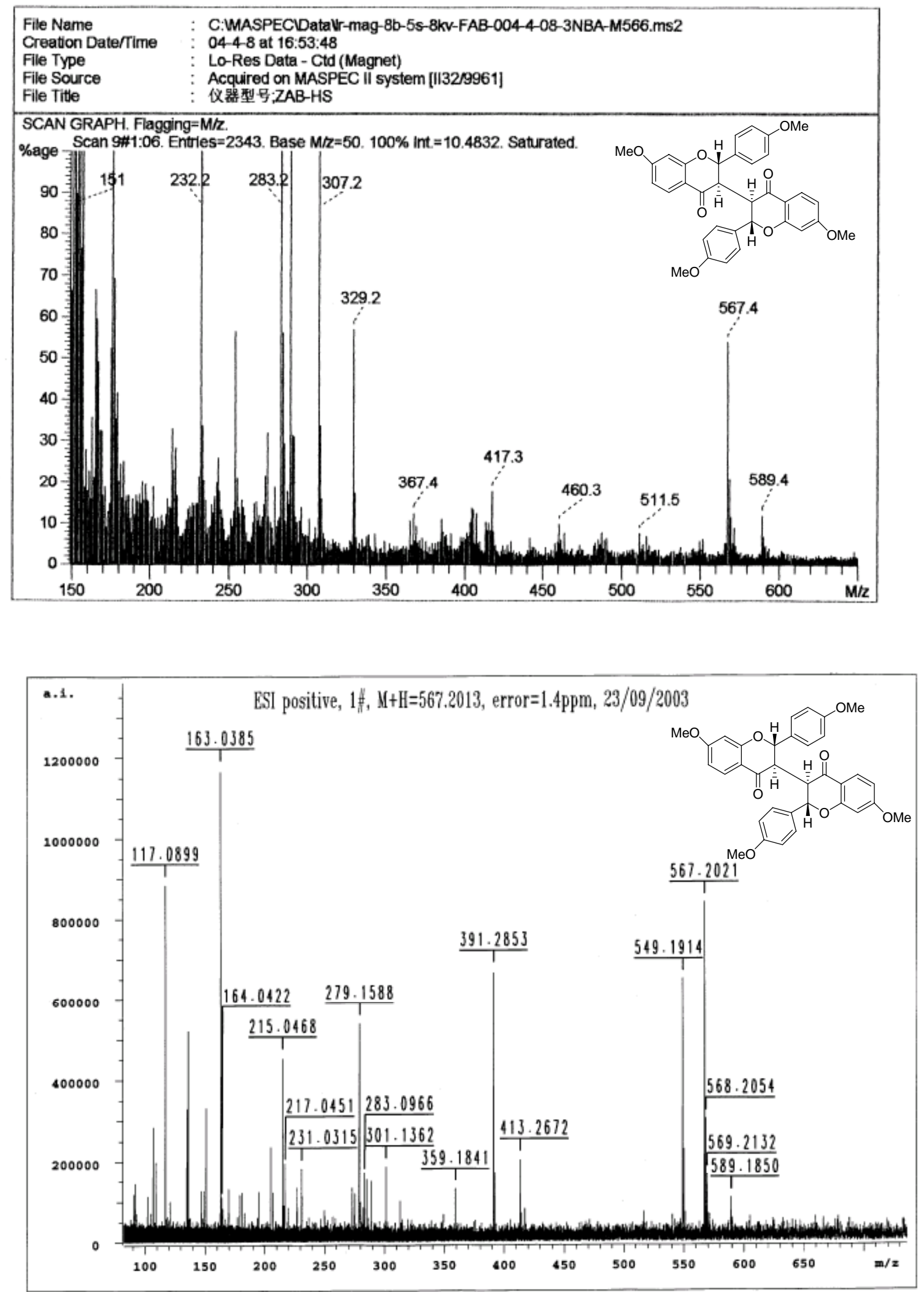

/u/data/TRAINING/mabaochong0923/1/pdata/1 xspec Tue SeD 23 15:51:22 2003 